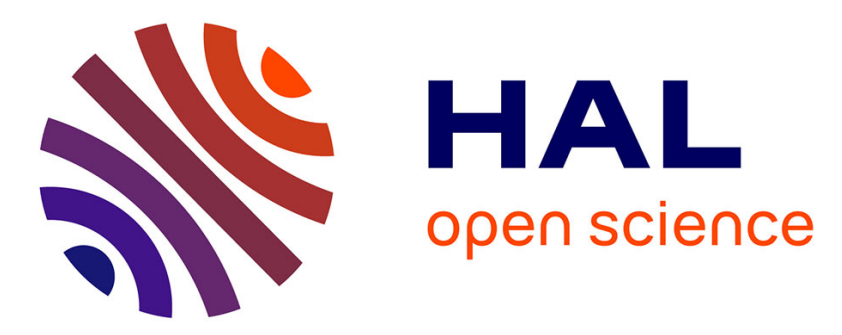

\title{
Assessing the collaboration and network additionality of innovation policies: a counterfactual approach to the French cluster policy
}

Konan Alain N'Ghauran, Corinne Autant-Bernard

\section{- To cite this version:}

Konan Alain N'Ghauran, Corinne Autant-Bernard. Assessing the collaboration and network additionality of innovation policies: a counterfactual approach to the French cluster policy. 2020. halshs$02482546 \mathrm{v} 2$

\author{
HAL Id: halshs-02482546 \\ https://shs.hal.science/halshs-02482546v2
}

Preprint submitted on 26 Feb 2020

HAL is a multi-disciplinary open access archive for the deposit and dissemination of scientific research documents, whether they are published or not. The documents may come from teaching and research institutions in France or abroad, or from public or private research centers.
L'archive ouverte pluridisciplinaire HAL, est destinée au dépôt et à la diffusion de documents scientifiques de niveau recherche, publiés ou non, émanant des établissements d'enseignement et de recherche français ou étrangers, des laboratoires publics ou privés. 
UMR 5824

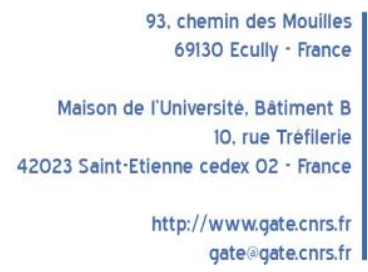

WP 2004 - Febuary 2020

\title{
Assessing the collaboration and network additionality of innovation policies: a counterfactual approach to the French cluster policy
}

Konan Alain N'Ghauran, Corinne Autant-Bernard

\begin{abstract}
:
Whereas most collaboration-based innovation policies aim at fostering efficient ecosystems of innovation, evaluations of the behavioural impact of such policies remain few and far between. Relying on external-to-thepolicy network data to build a counterfactual approach, this paper addresses three main evaluation issues: do cluster policies make firms more collaborative? Do they encourage local ties? Do they induce network additionality? Focusing on French data, our results suggest that cluster policies may lack effectiveness in tackling network failures.
\end{abstract}

\section{Keywords:}

Policy evaluation, Behavioural additionality, Organisational change, Counterfactual approach, Social network analysis, Cluster policy

JEL codes:

O32, O38, D04 


\title{
Assessing the collaboration and network additionality of innovation policies: a counterfactual approach to the French cluster policy
}

\author{
Konan Alain N'Ghauran ${ }^{1, *}$, Corinne Autant-Bernard ${ }^{1}$ \\ ${ }^{1}$ Univ Lyon, UJM Saint-Etienne, CNRS, GATE L-SE UMR 5824, F-42023 Saint-Etienne, France \\ *Main author for correspondence. Email: nghauran@gate.cnrs.fr
}

\begin{abstract}
Whereas most collaboration-based innovation policies aim at fostering efficient ecosystems of innovation, evaluations of the behavioural impact of such policies remain few and far between. Relying on external-to-the-policy network data to build a counterfactual approach, this paper addresses three main evaluation issues: do cluster policies make firms more collaborative? Do they encourage local ties? Do they induce network additionality? Focusing on French data, our results suggest that cluster policies may lack effectiveness in tackling network failures.
\end{abstract}

Keywords: Policy evaluation, Behavioural additionality, Organisational change, Counterfactual approach, Social network analysis, Cluster policy.

JEL code: O32, O38, D04 


\section{Introduction}

Of the various public intervention tools used to stimulate innovation, there is a growing interest in support for collaborative research. This is because collaborations can be an effective way of reducing market failures associated with the innovation process and of creating innovation ecosystems which are likely to reduce network failures. In this regard, the potential benefits of collaborative research are threefold (Hinloopen, 2001). First, by internalising technological spillovers, collaborative research reduces the "free rider" problem. Second, cooperation makes it possible to combine complementary skills to reach the critical mass required to implement very large research projects. Third, risk pooling may also lead to an increase in private R\&D activity. However, collaboration-based innovation policies do more than simply address market failures. As pointed out more recently by the literature on the innovation system (for an overview, see Bleda and Del Rio, 2013), systemic failures also arise. System failures refer to structural, institutional and regulatory deficiencies, which lead to sub-optimal investment in innovation activities. One of the main structural deficiencies is insufficient and/or inefficient levels of networking and knowledge exchange between organisations; these deficiencies are referred to as "network failures" and are an important component in the innovation policy agendas of regional, national and international institutions. Indeed, if organisations in a system interact poorly due to uncertainty and asymmetric information, this may hamper synergies, complementary knowhow, creative problem solving and capacity sharing, and lead to the lack of a shared vision of future technology developments. In addition to sub-optimal levels of cooperation, system failures may lead to inefficiencies in the network structure (Woolthuis et al. 2005). Due to cultural, technological or geographical distance, a lack of bridging ties is likely to occur, which prevents access to new knowledge, complementary expertise and resources. Due to asset specificity, the existence of switching costs or, in the case of monopolistic or high-tech markets, a lack of alternative partners, actors may be "locked into" their relationships. Public authorities can, therefore, give strong incentives to overcome this sub-optimal investment in collaboration or can establish an institutional context likely to provide firms with (new) collaboration opportunities. Gök and Elder (2012) refer to this as "behavioural additionality" in innovation policy. 
Among the rising tools developed to that purpose, cluster policies face a renewed interest and turns to be adapted to an increasingly wide variety of contexts and countries ${ }^{\mathrm{i}}$. According to the European Observatory for cluster and industrial change (2019), the French cluster programme is among the most developed one, with the largest budget in Europe.

However, the ability of public actors to shape firms' decision to create or delete alliances could be questioned. As stated by Tomasello et al. (2017), the process of network evolution is strongly pathdependent. Public incentives may therefore face difficulties to generate behavioural additionality. At the same time, the literature trying to assess the effectiveness of collaboration and network-based policies remains scarce and far between ${ }^{\text {ii }}$. This literature developed along two lines.

A first set of studies focuses on the policy impact on collaboration choices. They rely on surveys to identify the extent to which firms have increased the intensity of their collaboration or changed their type of partners. (Caloffi et al. ,2015; Wanzenböck et al., 2013; Afcha Chavez, 2011; Nishimura and Okamuro, 2011; Teirlink and Spithoven, 2012; Antonioli et al., 2014 and, more recently, Caloffi et al., 2018). In spite of the relevance of the counterfactual approach used by most of these authors, these studies are quite limited in terms of their ability to deal with some important aspects of the cluster policies. While focusing on collaboration additionality, they neglect the key issue of the overall structure of the network. Behind the political will to promote collaboration, the main goal is to encourage the structuration of the local eco-system. iii The actors' embeddedness within local and global networks is more important than simply the number of collaborations or the type of partner. The ability to promote key players at the national and international level, to encourage knowledge diffusion among various types of actors or across sectors, is not only a question of collaboration additionality - increase in the level of collaboration -, but more widely a question of network additionality - change in the network structure -. Considering collaboration is thus not sufficient to evaluate the policy impact. While increasing the level of collaboration, the policy may fail to trigger network embeddedness if collaboration increases only among actors already involved in past collaborations. For firms to become more central, the policy must modify the network of their relationship. 
This network dimension is better dealt with by a second set of studies which relies on social network analysis. Some recent papers by Giuliani et al. (2016), Calignano and Fitjar (2017) Rothgang et al. (2017) and Delio and Vicente (2019) belong to this line of research. Although these network-based approaches provide us with precise insights regarding the evolution of the structural properties of the subsidised network, they do not allow robust conclusions regarding the causal impact of the cluster policy to be drawn. While only relying on the network of beneficiaries, the pre- and post-treatment period comparison is not sufficient to identify the role played by the policy. Comparing various industries, Tomasello et al. (2017), observe some universal properties in the structural dynamics of R\&D network. Most of the changes in the collaboration and network features may thus occurred even in the absence of the policy. The general trend towards a more collective innovation could, for instance, be observed in more spontaneous networks and not only within publicly-supported clusters. Similarly, the more global dimension of inter-firm collaboration supported by the new communication technologies is likely to induce changes for firms both within and outside clusters. Change in the relationships between science and industry and in between small and large firms may also evolve over time due to drivers other than cluster policies. In addition, firms that have chosen to enter the cluster may have specific features and innovation strategies that may explain some structural evolutions of their network which would have occurred even in the absence of the policy.

The key issue is thus to identify the extent to which the cluster policy has changed the network features compared to what would have happened in the absence of the policy. This requires building a counterfactual network situation. This is the aim of this paper. As such, this paper adds to the innovation policy evaluation literature by suggesting an original approach combining programme evaluation methods and social network analysis. This is achieved by using internal and external data. "Internal" data refers to the cluster policy beneficiaries while "external" data covers both beneficiaries and nonbeneficiaries. It should be noted that the survey-based studies referred above (Afcha Chavez, 2011; Caloffi et al. 2018, etc.) also rely on both internal and external data. However, surveys do not make it possible to obtain information about the network. In the surveys, firms are asked about the number of their collaborations or the features of their partners, but it is not possible to draw conclusions from these 
answers as to the overall network relationships between actors. In this paper, we suggest relying on network information.

More specifically, we use patent data to build a counterfactual analysis to investigate whether cluster participation leads to a change in the innovation process itself. This approach also allows us to move from specific cluster case studies, often based on very few observations, to a broader cluster policy evaluation. While survey-based approaches and most previous network studies focus on a single cluster, our methodology is conceived in order to evaluate the entire national cluster policy. Patent data are used to observe individual collaboration and ego-network features and they are combined with firm data in order to identify individual features.

We also add to the counterfactual evaluation literature by relying on recent evaluation technics. We combine Inverse Probability of Treatment Weighting (IPTW) with the double-difference approach. Both conventional and machine learning - based technics (McCaffrey et al., 2004) are used to estimate the propensity score in order to build on the correct functional forms for each covariate and interactions between covariates (Stone and Tang, 2013). Following Bang and Robins (2005) and Kang and Schafer (2007), a doubly robust estimator of the average treatment effect is also provided to ensure that our estimator remains consistent if either the propensity score model or the outcome regression model is wrong. Finally, we rely on a method recently developed by Carnegie et al. (2016) to identify how much unmeasured confounding would produce a change in the conclusion of the study.

We focus on the French case since the French national cluster programme is among the most developed one in the world, and the largest one in Europe (with a budget of 144 million euros). The French context is also highly relevant because it covers most types of cluster policy features: it targets both lagging and leading regions and it relies on the three traditional roots of cluster policies: regional policy, science and technology policy and industrial/firm policy. The final sample includes 1,047 establishments owned by private, for-profit organisations, including 116 treated firms (cluster members) and 931 controls.

This original database is then used to address three main evaluation issues: do cluster policies make firms more collaborative? Do they encourage local ties? Do they induce network additionality? Our 
empirical results support the existence of a positive and significant effect of cluster membership on organisations' collaborative behaviour. During the period under study (2008-2010), cluster members increased their participation in collaborative $\mathrm{R} \& \mathrm{D}$ projects by 4.1 percentage points as a result of being members of French clusters, which is very high, given the low average propensity to co-invent. Our results also suggest that establishments with little or no prior experience in collaborative R\&D projects before joining clusters experienced a greater impact, increasing their participation in collaborative R\&D projects by 6.3 percentage points. However, we found no evidence that cluster members were more engaged in collaborations involving co-located partners, suggesting that clusters have failed to strengthen local ties. Moreover, we found no evidence to support a network additionality resulting from the French cluster policy. Cluster membership did not increase establishments' embeddedness into collaboration networks. In sum, our findings support the positive behavioural additionality effect of cluster policies but provide little evidence of the effectiveness of the French cluster policy in tackling network failures.

The remainder of paper is structured as follows. Section 2 recalls the rationale of cluster policies and sets out the hypotheses tested in the paper. Section 3 presents the programme under scrutiny. Section 4 describes the characteristics of our dataset and Section 5 discusses our empirical strategy. The results are presented and discussed in Section 6. Finally, Section 7 concludes and proposes avenues for further research.

\section{Conceptual framework and resulting hypotheses}

The need for innovation actors to actively engage in collaborations and the benefits of the geographical concentration of firms and economic actors have largely contributed to the expansion of cluster policies across the world. By promoting collaboration, these policies aim at enhancing the local innovation ecosystem. Their goal goes therefore beyond the mere desire to increase inter-organisation collaboration: it encompasses the structuration of efficient knowledge networks.

\subsection{Effects on collaboration}

The objectives of R\&D cooperation which are most often cited converge on the reduction of the inherent risks associated with $\mathrm{R} \& \mathrm{D}$ projects by i) promoting knowledge and cost-sharing between collaborators, 
ii) increasing the likelihood of successful R\&D activities and iii) internalising spillovers (Coase, 1960; D'Aspremont and Jacquemin, 1988). Collaboration is also a powerful way of generating new ideas in the innovation process through cross-fertilisation and creating knowledge complementarities. In this vein, interchanges between different organisations are essential, to the extent that Scherngell and Barber (2009) describe collaborations as a conditio sine qua non for innovation. Several empirical findings confirm the expected positive results of R\&D collaboration. Janz et al. (2003), Van Leeuwen (2002) and Criscuolo and Haskel (2003), for instance, find evidence of a positive correlation between R\&D collaborations and innovation performance, highlighting the importance of collaborative projects. The potential benefits of collaborative innovation justify the implementation of cluster policies that aim to encourage economic actors to engage in collaboration. Cluster members should, therefore, be more likely to be engaged in collaborative $\mathrm{R} \& \mathrm{D}$ projects than non-members, ceteris paribus. This behavioural change among clusters members should be observable both in their projects which are supported by the policy and in those which are not supported. Cluster policies should have a positive effect on the overall willingness of their members to collaborate, on other words, cluster members should be more open to collaborative innovation. However, obtaining an exact list of organisations' collaborations is not straightforward. To the extent that these R\&D projects lead to inventions, co-inventions can be considered as proxies for collaborations. We therefore put forward the following hypothesis concerning the effect of clusters on the collaborative behaviour of their members:

\section{H1: Cluster members are more engaged in co-inventions than non-members}

If, as we believe, cluster members are more engaged in co-inventions (with regards to the evolution of their inventive activity), we may conclude that clusters have succeeded in introducing their members to collaborative innovation.

\subsection{Effect on intra-regional collaboration}

Since Marshall (1920), it has been agreed that geographical concentrations of firms and economic actors can generate positive effects on economic growth in specific territories. Also known as "clusters", these kinds of geographical concentrations have been studied extensively in the framework of the New Geographical Economy promoted by Krugman (1991). According to the definition proposed by Porter 
(1998), a cluster is "a geographical proximate group of interconnected companies and associated institutions in a particular field, linked by commonalities and externalities”. Fernandez-Ribas (2009) claims that the implementation of science, technology and innovation (STI) policies at the local level is relevant for two reasons. The first is that regional and local governments tend to have a better understanding of the formal and informal institutions that shape behavioural patterns and social interactions in the territory. Lower levels of administrations are, therefore, needed to correct systemic dysfunctions linked to multi-level STI policies and they are in the best position to connect different stakeholders within the territory. The second reason concerns the capacity of sub-national governments to tailor national and supra-national policies. This is about guaranteeing the coherence between the various directions taken by the territory. Proximity effects also enhance collaboration intensity and knowledge flows between actors. As argued by Boschma (2005), these knowledge flows generate knowledge spillovers, innovation and, finally, regional growth.

Based on recent empirical evidence, the impact on the spatial scale of collaboration-based policies is not obvious. While analysing the impact of the EU Framework Programme on the intensity and geographical dimension of inter-regional collaborations, Scherngell and Lata (2013) observed that geographical distance and country border effects decrease over time. Due to the regional dimension of the data, they were, however, unable to implement a counterfactual analysis to properly assess the causality between the EU policy and the shape of collaboration networks. Conversely, based on concrete data and counterfactual analysis, Antonioli et al. (2014) found that funded firms are more likely to co-operate with regional partners than extra-regional ones. The spatial scale of the collaborations induced by the policy seems, therefore, to be driven by the geographic scope of the policy. It should be noted that there are other dimensions of proximity that can influence collaborations (e.g. cognitive, organisational, social and institutional proximities) and too much proximity may also have negative impacts on innovation due to lock-in problems (Boschma, 2005), particularly in the case of geographical proximity where regional actors do not share a minimal degree of cognitive (technical) proximity (De Noni et al., 2017). Despite the limits of too much geographical proximity, clusters that are designed based on Porter's definition are intended to strengthen intra-regional collaboration, regardless of whether they also 
reinforce inter-regional collaboration. It is expected that such clusters will strengthen collaborations between regional actors. Thus, we expect the following hypothesis to hold true:

H2: Cluster members are more engaged in co-inventions involving regional partners than non-members

It is worth noting that this hypothesis does not imply that clusters are not supposed also to support collaboration with non-regional partners. It is simply the result of the Porter's definition of clusters which implies the strengthening of interactions between geographically-proximate organisations. Since most clusters are designed following this definition and at a regional level, they are intended to support networking among regional organisations but also between regional and non-regional organisations. If cluster members are more engaged in co-inventions (with regard to the evolution of their inventive activity) with regional partners, we may conclude that clusters have succeeded in strengthening the territorial anchoring of their members through collaborative innovation.

\subsection{Effect on network embeddedness}

In addition to the advantages of both $\mathrm{R} \& \mathrm{D}$ cooperation and favourable regional conditions such as Marshallian localisation externalities (Asheim et al., 2006) and socio-cultural or institutional embeddedness (Armin and Thrift, 1994), Broekel et al. (2015) showed that clusters also grant their members an additional premium to their membership in two ways. First, cluster members are more likely to receive $R \& D$ subsidies compared to non-members. ${ }^{\text {iv }}$ Second, they are more embedded in networks of subsidised R\&D collaboration. Broekel et al. (2015) argue that since cluster members are more likely to participate in subsidised joint R\&D projects, they should be differently embedded into networks of subsidised R\&D projects compared to non-members. Based on the German biotechnology industry and using projects funded under the $6^{\text {th }}$ EU-Framework Programmes (EU-FP) and national R\&D subsidisation schemes, the authors found that biotechnology firms in clusters hold more prominent positions in the national networks of subsidised $\mathrm{R} \& \mathrm{D}$ projects compared to firms outside clusters, even though they do not collaborate with a large number of partners.

However, Broekel et al. (2015) do not focus on cluster policies. They consider clusters in biotech based on the spatial density of biotech patents in each area. In addition, in this study, networks are built from 
national and EU subsidised projects. Now the fact that they are well embedded in networks of subsidised $R \& D$ projects does not mean that cluster members are also well embedded in non-subsidised $R \& D$ projects, since the allocation of $R \& D$ subsidies could be biased in favour of cluster members. This centrality is important since more centrally located firms will demonstrate superior performance, to the extent that such a location facilitates the accumulation of resources (Powell et al., 1996). This idea has its roots in the theoretical literature on social network analysis (Coleman, 1988; Burt, 1992; Ahuja et al. 2012) as well as in several pieces of empirical evidence (see for instance Ahuja, 2000, Reagans and Zuckerman 2001, Burt, 2004, Reagans et al., 2004, Tortoriello and Krackhardt, 2010, Phelps 2010, Mors 2010). The actors' positions within networks have been proved to be strongly correlated to the actors' level of performance. The various types of services provided by clusters could contribute to this goal by helping local organisations to increase their network embeddedness (Martin and Sundley, 2003). For instance, most cluster policies appoint brokers and intermediaries to organise the coordination between actors. This should improve the ability of actors to identify relevant networks. It is also argued that cluster policies involve collective marketing of the region's industrial strengths. Raising awareness of local industrial specialisms makes local firms more likely to be asked to enter national and international partnerships and therefore to increase their centrality within knowledge networks. As argued by Martin and Sundley (2003), cluster policies should also identify weaknesses in existing cluster value chains and attract investors and businesses to fill those gaps. Such an attractiveness policy could strengthen the network positioning of local anchor firms by reinforcing their demand and supply links.

To this respect, an effective policy is a policy that modifies the position of the funded firms in the network of its relationship, making it more central. In case a cluster policy increases the level of collaboration among actors already involved in past collaborations, the firm' centrality level would remain rather unchanged. Conversely in case policy incentives succeed to broaden the set of collaborators, then the centrality could increase, providing the firm with a better access to local and global knowledge. Indeed, as stressed in recent social network literature (Everett and Valente, 2016) brokerage positions are strongly correlated with centrality. Increasing the ability of funded firms to connect previously unconnected agents (brokerage) thus modifies the network structure and favours 
knowledge diffusion. Our third hypothesis therefore aims at investigating whether there is actually a cluster premium regarding the embeddedness of cluster members into networks of co-inventions. We put forward the following hypothesis:

\section{H3: Cluster members are better embedded in networks of co-inventions than non-members}

To test hypotheses H1, H2 and H3 it would be insufficient to compare changes in the ability of cluster members and non-members to collaborate and to be embedded into networks. To estimate the causal effect of cluster membership, we need to account for the fact that organisations which decide to join clusters are not necessarily comparable to those which do not. Our empirical strategy will be described in Section 5 after setting out information on the empirical field and the data.

\section{French cluster policy}

Our empirical analysis focuses on the French cluster policy which was launched in 2005 to raise the country's innovative capacity. This policy is part of a broad industrial ambition in France aiming at a better combination of innovation and industry than in the past, within regions.

\subsection{Aim and scope of the French cluster policy}

According to an official definition, a (French) cluster "brings together large and small firms, research laboratories and educational establishments, all working together in a specific region to develop synergies and cooperative efforts" ${ }^{\prime}$. French clusters are intended to actively support networking between firms, universities and research organisations mainly at the regional level, although clusters are also encouraged over time to increase networking between their members and actors from others regions.

In July 2005, the French government established 67 clusters in various fields (energy, mechanics, aerospace, transport, ICTs, health, environment, ecotechnology, etc.). After the creation of new ones and the merger of some of them over time, the number of clusters stood at 71 in 2014 and 56 today in various fields (energy, mechanics, aerospace, transport, ICTs, health, environment, ecotechnology, etc.). In 2014, the 71 clusters had about 9,650 company-level members (for 10,380 individual establishments) including 8,500 private firms and 1,150 public research organizations (DGE, 2017). Even though the 
French clusters are open to all firms no matter their size, the majority of private cluster members are SMEs: in 2014, $75 \%$ of the members were establishments owned by SMEs, $17 \%$ by mid-tier firms and $8 \%$ by large firms (DGE, 2017).

The State support for clusters mainly takes the form of i) a partial financing of cluster governance structures, alongside local authorities and members (public research organisations and firms), and ii) the granting of financial assistance to collaborative R\&D projects emerging from clusters. Between 2005 and $2013,1,313$ collaborative R\&D projects endorsed by clusters received public financing of $€ 2.37$ billion, including more than $€ 1.45$ billion granted by the French State through the Single Inter-Ministry Fund (FUI). However, despite these huge amounts of money allocations, the French cluster policy is not the most expensive area of state activity innovation policies.

The national innovation support system is essentially based on indirect aids through the research tax credit (CIR), the cost of which amounted to $€ 6.3$ billion in 2015 , i.e. nearly $75 \%$ of the state's support for innovation, compared to $16.5 \%$ in 2000 (CNEPI, 2016). French clusters get their support mostly from financial instruments such as subsidies and they capture less and less public funding since their creation. However, this does not call into question the importance of the clusters in the national innovation system since they are one of the major policy instruments (in terms of financial allocation) from the national innovation strategy designed to support collaborative R\&D projects and local innovation ecosystems, particularly before the 2010s. Since 2010, several other policy instruments such as the Technology Transfer Accelerator Offices (SATT) and the Technology Research Institutes (IRT) have been implemented to also support collaborative research, the strengthening of science-industry collaboration and technology transfer.

\subsection{The various phases of the French cluster policy}

Like many cluster policies, the French policy was implemented following the logical framework approach, which is based on the theoretical arguments justifying the implementation of cluster policies, described in Section 2. This framework, therefore, provides a relevant picture of what was expected from French clusters in terms of supporting networking. However, despite the relevance of the 
conceptual framework mentioned above, the French cluster policy has had some specific goals and objectives that would be worth clarifying.

The first phase of the policy (2005-2008) was essentially focused on structuring the clusters and the emergence of collaborative R\&D projects within them. During this phase, the policymakers' aim was to propose to innovation actors a new model of carrying out R\&D projects based on collaborations with other actors, particularly in co-located organisations. Clusters were, therefore, intended to act as incubators for collaborative $R \& D$ projects involving firms, universities and research organisations. Following the theoretical arguments in favour of strengthening collaborations between co-located organisations for economic growth, policymakers opted for a regional anchoring of clusters. This anchoring materialised in the adequacy between clusters' fields of specialisation and the economic sectors present in regions, as well as the research themes led by the regional public research actors. In order to support this vision, regional authorities were heavily involved from the beginning of the policy, particularly in terms of providing joint funding, alongside State financing. In addition to the strengthening of the local innovation ecosystem, the political will is to favour the national and international visibility of local actors. A distinction was made between world clusters, world vocation clusters and national clusters in order to support the participation in international projects (especially European projects) as well as the promotion of innovative local actors. To this respect, the cluster policy aims at helping cluster members to hold more central positions within knowledge and innovation networks

During the second phase of the policy (2009-2012), however, both the territorial and the international dimension have been revisited. The territorial anchoring of clusters has been relaxed to create synergies between them and all the other policies and actors supporting innovation both at national and local levels. The purpose of this new direction was to strengthen the consistency between innovation policies in France in order to build more relevant and resilient innovation ecosystems. This new strategy implied that clusters would be more open to long-distance collaborations and not only collaborations with regional actors. For policymakers, reinforcing the synergies between clusters must also be an inherent part of the cluster policy to avoid duplication of R\&D efforts. Beyond the theoretical arguments 
supporting long-distance collaborations, the logic of optimising R\&D efforts was even more crucial in a significantly deteriorated economic context due to the economic crisis of 2008. The previous distinction between world clusters, world vocation clusters and national clusters has been removed but the political will to favour the national and international visibility of local actors has remained. Thus networking of innovation stakeholders remained as a main concern during the second phase of the cluster policy.

The following phase (2013-2018) built on the previous direction to reinforce collaborations between firms, universities and research organisations but the main objective of the clusters then became was to turn more towards their economic impact. This objective emerged from the recommendations of several evaluations of French clusters (Technopolis group et al., 2012; Fontagné et al., 2013; Ben Hassine and Mathieu, 2017) implemented by both practitioners and scholars. These studies revealed that the French cluster policy have had a positive effect on increasing innovation inputs (firms' R\&D expenditures and employment of R\&D staff). However, when it came to innovation outputs (granted patents, turnover, added value, employment, exports, etc.), evaluators found different results and, overall, there is little evidence of the positive effects of the policy on firms' performance. This lack of evidence has contributed to a growing scepticism towards the French clusters to the point where Ben Hassine and Mathieu (2017) refer to this as a "curse". In this context, evaluators were unanimous in recommending that the government continues funding clusters while looking for increases in their economic impacts.

The current context is also marked by the merger of some clusters and the co-endorsement of collaborative R\&D projects by clusters. Previously organised into independent entities although maintaining close links, some clusters now tend to be increasingly structured around a single, unifying governance structure. In addition to policymakers' desire to encourage relations between clusters, this dynamic was also supported by the merging of certain French regions in 2016. Several clusters that were previously located in different regions have thus seen their scope of action becoming shared with other clusters. There is every indication that the future of French clusters would be marked by a greater openness towards (long-) distant collaborations, which implies cluster members collaborating with actors that are not necessarily located within their region. Such a political orientation would potentially 
result in a decrease in local collaborations. The most recent call for applications concerning the selection of clusters for the forth phase (2019-2022) was recently launched. The call specifies that this phase will be designed from a more European perspective, in order to develop collaborative projects with European actors within the context of Horizon 2020 and Horizon Europe calls for tenders. This implies a stronger embeddedness of cluster members into global innovation networks.

This clearly shows how French clusters have increasingly turned towards supporting collaborations (whether distant or otherwise), sometimes to the detriment of their regional roots, which was one of the foundations of their establishment. This change led to a debate on the role of clusters for regional development. Given the theoretical arguments justifying interregional and intraregional collaborations, both forms of collaboration have to be supported and the former should not be at the expense of the latter (De Noni et al., 2017). The hypotheses tested in this paper will allow us to assess to what extent French clusters have pushed their members to engage in collaborative $R \& D$ projects with other actors on the one hand, and with co-located partners on the other and whether this induces a change in actors' embeddedness within innovation networks. Focusing on firm data, this paper addresses the key issue of the impact of the policy on the private sector engagement, which is acknowledged as a critical factor of success of such policies (OECD, 2007).

\section{Data and outcome variables}

As detailed below in Section 6, our empirical strategy consists in building a counterfactual approach in order to assess the existence of collaboration and the network additionality of the French cluster policy. This approach requires finding external-to-the-policy network data in order to outline the network of knowledge collaboration. This will allow us to characterise the collaboration and network behaviour of both beneficiaries and non-beneficiaries of the cluster policy.

\subsection{Building the network of collaboration}

Co-invention networks (hereafter used interchangeably with "collaboration networks") are based on applications for patents submitted to the French patent office (INPI) over the period 2008-2013. We use a three-year lag between the beginning of $\mathrm{R} \& \mathrm{D}$ projects and patent applications. The choice of this 
three-year lag is justified by the average duration of $R \& D$ projects supported by clusters through the FUI, which is one of the main instruments for financing collaborative R\&D projects from French clusters. In line with the vision of turning clusters into drivers of growth and competitiveness, the FUI mainly supports pre-competitive $R \& D$ projects aiming at placing new products and services on the market within three to five years from the end of projects. Thus, within the FUI scheme, several clusters support $R \& D$ projects with an average duration of three years ${ }^{\mathrm{vi}}$ in order to target projects that are innovative but also "close to the market". Moreover, firms that are cluster members are mainly industrial actors involved in more applied $R \& D$ projects. In this context, we consider this average duration of $\mathrm{R} \& \mathrm{D}$ projects supported through the FUI as being representative of the average duration of cluster members' $R \& D$ projects. The choice of a three-year lag between the beginning of $R \& D$ projects and patent applications is also supported by previous studies on duration of R\&D alliances (Phlippen and van der Knaap, 2007; Phelps, 2010).

When defining the pre- and post-treatment periods, we faced some challenges related to the short life span of firms' establishments. In order to have the largest sample of cluster members, we considered 2008 as the date of treatment, and cluster members before 2008 were excluded from the sample. Considering the actual date of the cluster's creation, such as 2005, results in a small sample size, since clusters had few members when they were established and many of those members were young establishments for which information on the pre-policy period cannot be obtained. Based on a threeyear lag between the beginning of R\&D projects and patent applications, we then considered that patent applications between 2008 and 2013 were the result of projects that started during the 2005-2010 period. This time span was broken down into two three-year periods: 2005-2007 and 2008-2010, which are respectively the pre- and post-treatment periods. Our treated population is, therefore, firms' establishments involved in clusters between 2008 and 2010, but not before 2008 .

Primary patent data provides us with information on applicants on the one hand and information on inventors on the other. Due to the multi-site nature of public or private organisations/firms (which are usually the patent applicants), the geographic addresses available on patent applications do not allow us to locate the places where inventions were actually made, i.e., the locations of establishments which 
effectively carried the R\&D projects. In order to identify these locations, we had to rely on two assumptions. Based on the distribution of patents between inventors and applicants during each period, we first identified the organisation employing each inventor following this assumption:

\section{A1: an inventor belongs to an organisation when they file most of their patents with that organisation} and that organisation alone.

This assumption relies on the fact that the majority of inventors are employed by an organisation (European Patent Office, 2011), which is usually, although not systematically, the patent applicant. We assume that the more an inventor's name appears in a set of patents (excluding co-patents) alongside a given applicant, the more likely this inventor is to be an employee of that applicant. Based on the addresses of inventors and establishments, we then identify the establishment employing each inventor following this second assumption:

A2: an inventor belongs to their organisation's establishment which is geographically closest to them.

Following Blomkvist et al. (2014), there are good reasons to assume that inventors live near their places of work, since they want their activities to remain within easy commuting distance of home (Zucker et al., 1998). This assumption is highly plausible in the French context, since in 2004 for instance, half of all employees worked within eight kilometres of their home (Baccaïni et al., 2007). For employees whose workplace is not in their commune of residence, the National Institute of Statistics and Economic Studies indicated that the distance between home and work increased by only $2 \mathrm{~km}$ between 1999 and 2013 (Coudène et al., 2016).

By combining assumptions 1 and 2, we translate collaboration networks among organisations into collaboration networks among establishments, which allows for a more realistic geographical representation of collaboration networks. The final collaboration networks are therefore portrayed using nodes which represent establishments and edges connect pairs of nodes which are the co-inventors of at least one patent. Isolated nodes or establishments are patent owners which are not involved in any coinvention. 


\subsection{Characterising individual collaboration and network features}

Based on these collaboration networks, we can calculate the number of inventions and co-inventions of each establishment before and after joining clusters. Since the periods under study (2005-2007 and 2008-2010) are relatively short, it is important to analyse the collaborative and network behaviour of establishments with regard to their inventive activity over this timespan. For each establishment in the network, we calculated i) its co-invention rate (to test $\mathrm{H} 1)$; ii) its intra-regional co-invention rate $(\mathrm{H} 2)$ and iii) its degree centrality and betweenness centrality (H3) during the pre- and post-treatment periods.

The co-invention rate can be defined as the propensity of an establishment to be engaged in co-invention while the intra-regional co-invention rate is the propensity of an establishment to be engaged in coinvention with co-located partners. We take into account all type of organisations (private or public) when computing these rates. Therefore, establishments' partners are not limited to establishments owned by private organisations. These rates are our outcome variables. The co-invention rate is formulated as follows:

$$
\text { co. invention rate } \text { ri,t }=\frac{\operatorname{coinv}_{i, t}}{\operatorname{inv}_{i, t}}
$$

where $\operatorname{coinv}_{i, t}$ and $i n v_{i, t}$ are, respectively, the number of co-inventions and the total number of inventions (including co-inventions) of establishment $i$ over period $t$, a dummy variable equal to 1 after the policy. $i n v_{i, t}$ therefore, refers to the total number of inventions individually developed or not developed, while $\operatorname{coinv}_{i, t}$ is the number of inventions developed by an establishment with at least one establishment from a different firm or organisation.

Building on the above definition of the co-invention rate, the intra-regional co-invention rate has as numerator only co-inventions involving at least one co-located establishment and is formulated as follows:

$$
\text { intra.regional co. invention rate } e_{i, t}=\frac{\text { intra.regional. } \operatorname{coinv}_{i, t}}{\operatorname{inv}_{i, t}},
$$

where intra. regional. $\operatorname{coinv}_{i, t}$ is the subset of co-inventions consisting of those involving at least one co-located establishment from a different firm or organisation. 
In order to test the third hypothesis (H3), we rely on networks centrality measures. Following Broekel et al. (2015), we use the degree centrality and the betweenness centrality to respectively proxy the degree and the quality of establishment's embeddedness in innovation networks.

The degree centrality is a simple count of establishments' number of direct collaboration partners and therefore provides a quantitative expression of their local network embeddedness; Broekel et al. (2015) referred to this local embeddedness as local centrality. The degree centrality of a node $i$, for a given non-directed network $N:=(V, E)$ with $V$ nodes and $E$ edges is denoted as:

$$
C_{D}(i)=\operatorname{deg}(i)
$$

Unlike the degree centrality, the betweenness centrality goes beyond establishments' direct collaboration. In the social network analysis literature, the "betweenness centrality" refers to the number of times a node lies on the shortest path between other nodes (Freeman 1987; Wasserman and Faust 1994). It therefore takes into account indirect ties and approximates the extent to which establishments act as "bridge" between other establishments in the network; Broekel et al. (2015) referred to this bridging position as global centrality. The betweenness centrality of a node $i$, for a given non-directed network $N:=(V, E)$ with $V$ nodes and $E$ edges is defined as:

$$
C_{B}(i)=\sum_{j \neq i \neq k} \frac{g_{j k}(i)}{g_{j k}}
$$

where, $g_{j k}(i)$ is the number of shortest paths connecting $j$ and $k$ passing through $i$ and $g_{j k}$ the total number of shortest paths connecting $j$ and $k$.

After computing these four outcome variables from collaboration networks, we expanded the dataset by including characteristics from the DADS ${ }^{\text {vii }}$ database. We retrieved from this database the establishments' number of employees as well as their qualifications. The final sample included 1,047 establishments owned by private for-profit organisations. ${ }^{\text {viii }}$ These 1,047 private establishments included 116 which were treated (they had been cluster members for at least one year between 2008 and 2010 and were not cluster members before 2008), and 931 controls (non-cluster members over the 2005-2010 period). 


\subsection{Beneficiaries vs non-beneficiaries characteristics}

All the baseline characteristics as well as the outcome variables before cluster membership are listed in

Table 1, along with their mean and standard deviation, and their proportions (for categorical variables) in both populations.

From Table 1, there was not too much difference between the treated and control groups regarding their co-invention rate and their intra-regional co-invention rate before the treatment. Regarding the centrality measures, cluster members had less direct ties compared to non-cluster members (degree centrality) but they have acted more as "bridges" between other establishments in the collaboration network (betweenness centrality). Treated establishments also had partially different background characteristics from controls before joining clusters. Indeed, cluster members are much larger establishments in terms of the number of employees than controls. They also have a higher proportion of highly-qualified employees and are much more present in high-technology sectors. Overall, these differences may reflect a selection bias that should be addressed before making any causal inference. 
Table 1. Baseline characteristics of treated and control subjects in the original sample

\begin{tabular}{|c|c|c|}
\hline \multirow[b]{2}{*}{ Variable } & \multicolumn{2}{|c|}{ Cluster members: } \\
\hline & $\begin{array}{c}\text { No } \\
(\mathrm{N}=931)\end{array}$ & $\begin{array}{c}\text { Yes } \\
(\mathbf{N}=116)\end{array}$ \\
\hline Size & $216.73(493.09)$ & $401.84(629.14)$ \\
\hline Highly-qualified employees & $0.26(0.25)$ & $0.30(0.21)$ \\
\hline Number of inventions & $11.40(32.17)$ & $23.37(88.68)$ \\
\hline \multicolumn{3}{|l|}{ Technological intensity } \\
\hline High-technology & $43(4.6 \%)$ & $17(14.7 \%)$ \\
\hline Knowledge-intensive services (KIS) & $184(19.8 \%)$ & $21(18.1 \%)$ \\
\hline Less knowledge-intensive services (LKIS) & $105(11.3 \%)$ & $6(5.2 \%)$ \\
\hline Low technology & $81(8.7 \%)$ & $14(12.1 \%)$ \\
\hline Medium-high technology & $325(34.9 \%)$ & $41(35.3 \%)$ \\
\hline Medium-low technology & $193(20.7 \%)$ & $17(14.7 \%)$ \\
\hline \multicolumn{3}{|l|}{ Firm's type of establishment } \\
\hline Large enterprises & $302(32.4 \%)$ & $34(29.3 \%)$ \\
\hline Micro enterprises & $23(2.5 \%)$ & $3(2.6 \%)$ \\
\hline Intermediate-sized enterprises & $345(37.1 \%)$ & $48(41.4 \%)$ \\
\hline Small and medium-sized enterprises & $261(28.0 \%)$ & $31(26.7 \%)$ \\
\hline \multicolumn{3}{|l|}{ Region } \\
\hline Alsace & $25(2.7 \%)$ & $1.0(0.9 \%)$ \\
\hline Aquitaine & $31(3.3 \%)$ & $3(2.6 \%)$ \\
\hline Auvergne & $18(1.9 \%)$ & $1.0(0.9 \%)$ \\
\hline Basse-Normandie & $16(1.7 \%)$ & $2.0(1.7 \%)$ \\
\hline Bourgogne & $23(2.5 \%)$ & $6(5.2 \%)$ \\
\hline Bretagne & $47(5.0 \%)$ & $3(2.6 \%)$ \\
\hline Centre & $36(3.9 \%)$ & $5(4.3 \%)$ \\
\hline Champagne & $25(2.7 \%)$ & $4(3.4 \%)$ \\
\hline Franche-Comté & $22(2.4 \%)$ & $4(3.4 \%)$ \\
\hline Haute-Normandie & $22(2.4 \%)$ & $3(2.6 \%)$ \\
\hline Ile-de-France & $233(25.0 \%)$ & $27(23.3 \%)$ \\
\hline Languedoc & $14(1.5 \%)$ & $3(2.6 \%)$ \\
\hline Limousin & $3(0.3 \%)$ & $1.0(0.9 \%)$ \\
\hline Lorraine & $22(2.4 \%)$ & $2.0(1.7 \%)$ \\
\hline Midi-Pyrénées & $27(2.9 \%)$ & $6(5.2 \%)$ \\
\hline Nord & $33(3.5 \%)$ & $3(2.6 \%)$ \\
\hline Normandie & $3(0.3 \%)$ & $1.0(0.9 \%)$ \\
\hline Pays-de-la-Loire & $58(6.2 \%)$ & $4(3.4 \%)$ \\
\hline Picardie & $35(3.8 \%)$ & $1.0(0.9 \%)$ \\
\hline Poitou-Charente & $29(3.1 \%)$ & $2.0(1.7 \%)$ \\
\hline Provence-Alpes-Côte d'Azur & $31(3.3 \%)$ & $7(6.0 \%)$ \\
\hline Rhône-Alpes & $178(19.1 \%)$ & $27(23.3 \%)$ \\
\hline \multicolumn{3}{|l|}{ OUTCOMES } \\
\hline Co-invention rate & $0.04(0.14)$ & $0.05(0.13)$ \\
\hline Intra-regional co-invention rate & $0.02(0.09)$ & $0.02(0.08)$ \\
\hline Degree centrality & $2.43(5.22)$ & $2.10(4.65)$ \\
\hline Betweenness centrality & $1301.33(5107.99)$ & 2492 (174498.06) \\
\hline
\end{tabular}

Note: Continuous variables are represented as mean and standard deviation (in parentheses), while dichotomous variables are represented as $\mathrm{N}(\%)$. 


\section{Empirical strategy}

\subsection{Econometric approach}

Our objective is to identify the average mean effect of treatment (on the treated - ATT) on the coinvention rate, the intra-regional co-invention rate and the centrality (degree and betweenness) of cluster members. Following Rubin's causal model (Rubin, 1974), finding a reliable estimate for the counterfactual state, i.e., the outcome if participants had not participated in the programme, is the primary task of any evaluation study. This way of defining treatment effects is often referred to as the "potential outcomes approach" (Rubin, 1978, 1980). The main challenge of such an evaluation is to find a reliable estimate for the counterfactual state, i.e. the outcome if cluster members had not joined the clusters. For any establishment $i$, the causal effect of $Z$ on $Y$ is:

$$
Y_{i}(Z=1, X)-Y_{i}(Z=0, X) \text {, }
$$

where $X$ includes any influence on $Y$ other than the treatment $Z$. However, we can never observe this causal effect directly because we cannot simultaneously observe the same unit with and without the treatment condition. The evaluation methodology used in this paper is based on the combination of Inverse Probability of Treatment Weighting (IPTW) with the double-difference approach. As a propensity score method, IPTW is based on the propensity score which is defined as the subject's probability of treatment selection, conditional on observed baseline covariates i.e., $e(X)=P(Z=1 \mid X)$. Propensity scores are estimated using a probit regression and we refer to this model as the "simple specification of propensity score model":

$$
P\left(Z=1 \mid X_{i}\right)=\Phi\left(\sum_{k=0}^{K} \beta_{k} X_{i k}\right),
$$

where $Z_{i}$ is a treatment indicator, taking values of 1 for the treated and 0 for the untreated; $X$ is a vector of $K$ number of observed measures that predict the probability of joining clusters for each establishment i. $\beta$ denotes a set of coefficients that estimates the relationship between the covariates and the probability of being cluster members, under the cumulative normal distribution $\Phi$.

Models developed using probit regression may not produce the best propensity scores (Dehejia and Wahba, 1999; Olmos and Govindasamy, 2015). Following the recent development of machine learning 
techniques applied to causal analyses, McCaffrey et al. (2004) also suggested an alternative approach to estimating propensity scores using Generalised Boosted Models (GBM). GBMs are multivariate nonparametric techniques that recursively partition the data for each covariate and predict treatment assignment based on decision trees. GBMs use the "forward stagewise additive algorithm" (Abdia, 2017) to estimate the propensity score by modelling:

$$
g\left(X_{i}\right)=\operatorname{logit}\left(e\left(X_{i}\right)\right)=\log \left(\frac{e\left(X_{i}\right)}{1-e\left(X_{i}\right)}\right)
$$

where $X$ is the vector of covariates and $e(X)$ the propensity score. McCaffrey et al. (2004) argued that GBMs are particularly suited to estimating propensity scores in the presence of a large number of pretreatment covariates and also when covariates are non-linearly related with the treatment assignment. The main advantage of this approach over a simple specification of treatment assignment mechanism is that generalised boosted-regression modelling builds on the correct functional forms for each covariate and interactions between covariates, that are not fully specified in a simple specification such as a probit regression (Stone and Tang, 2013). We estimated another set of propensity scores using a generalised boosted model and refer to this model as the "complex specification of propensity score model".

By using two propensity score models, we aim to compare (and then select) the one that achieves the best balance in terms of baseline covariates between treated and control groups. Moreover, a high correlation between the propensity scores obtained in both specifications would suggest a good specification of the probit regression.

The purpose of IPTW is to create a pseudo-population of both treated and control groups, with the same covariate distribution. By doing this, IPTW mimics a randomised experiment (Austin and Stuart, 2015). Treated and control units are therefore weighted in order to balance covariate distribution in both groups. To estimate the ATT, the weight $w_{i}$ for each establishment is defined as:

$$
w_{i}=Z_{i}+\frac{\left(1-Z_{i}\right) e_{i}(X)}{1-e_{i}(X)}
$$

Equation [8] leads to weights of 1 for treated and $\frac{e_{i}(X)}{1-e_{i}(X)}$ for controls. Two weighted samples are then created based on estimated propensity scores from the simple and complex specifications. All the 
estimates involving each of these weighted samples are actually based on 1,000 bootstrapped samples. We rely on the standardised mean difference (SMD) to assess the balance in baseline characteristics between treated and control groups (Austin and Stuart, 2015; Caloffi et al., 2018). While there is no consensus as to what value of a standardised mean difference can be considered as an indication of imbalance, several authors have suggested that a standardised mean difference in excess of 0.1 may be indicative of meaningful imbalance in a covariate between treated and control subjects (e.g. Normand et al., 2001; Mamdani et al., 2005; Austin and Stuart, 2015).

Despite its ability to mimic randomised experiments, IPTW alone is not sufficient for an unbiased estimate of the ATT, since time-invariant unobserved characteristics may still contribute to selection bias. Therefore, we rely on the double-difference framework which is based on a comparison of treated and controls before and after the intervention to control for those unobservable characteristics. The difference-in-differences (DD) estimator is defined as the difference in average outcome of the treatment group minus the difference in average outcome in the control group before and after treatment. The estimate is constructed as follows:

$$
\left(\bar{Y}_{i(Z=1), t=1}-\bar{Y}_{i(Z=1), t=0}\right)-\left(\bar{Y}_{i(Z=0), t=1}-\bar{Y}_{i(Z=0), t=0}\right)
$$

We base our estimation procedure on the first difference i.e., the difference between two time points as a dependent variable. The second difference comes from our treatment variable. Our response model is therefore defined as follows:

$$
\Delta Y_{i}=Y_{i, t=1}-Y_{i, t=0}=\alpha+\delta_{A T T} Z_{i}+\varepsilon_{i, t}
$$

where $\Delta Y_{i}$ is the change in the outcome of interest, $\delta$ the coefficient of interest (treatment effect) and $\alpha$ the time trend. One should note that this estimate of the treatment effect with propensity score weighting is also the difference between the weighted means of the outcome for treated and untreated establishments (Imbens, 2004):

$$
\widehat{\delta_{A T T}}=\frac{\sum_{i=1}^{n} Z_{i} \Delta Y_{i}}{\sum_{i=1}^{n} Z_{i}}-\frac{\sum_{i=1}^{n}\left(1-Z_{i}\right) \Delta Y_{i} e\left(X_{i}\right) /\left(1-e\left(X_{i}\right)\right)}{\sum_{i=1}^{n}\left(1-Z_{i}\right) e\left(X_{i}\right) /\left(1-e\left(X_{i}\right)\right)},
$$

The literature on cluster policy evaluation suggests that qualitative methods could be a better approach for evaluating behavioural additionality (Falck et al., 2010). This is partially due to the fact that changes 
in establishments' behaviour could also come from their participation in subsidised R\&D projects, not just from the cluster policy. However, it is not straightforward to identify which establishments have received any support for collaborative $\mathrm{R} \& \mathrm{D}$ projects before the policy given the large number of funding schemes available. Nevertheless, one can assume that establishments receiving this kind of support are those that show some interest in collaborative $R \& D$ projects. In order to differentiate these establishments from others, we propose a qualitative measure, collaborative establishment $t_{i, t=0}$, identifying which establishments are interested in collaborative projects during the pre-policy period $(2005-2007)^{\mathrm{ix}}$. This measure is a dummy variable constructed as follows:

$$
\text { collaborative establishment }_{i, t=0}=\left\{\begin{array}{c}
\text { Yes, } \begin{array}{c}
\text { if co. invention rate } \\
\text { No, }=0
\end{array}>0 \\
\text { No, otherwise }
\end{array}\right.
$$

In order to better address this attributability challenge, we also consider establishments' participation to the EU's Framework Programme (FP). Indeed, as a key policy instrument to support medium- to largesized collaborative research projects in Europe, Framework Programme is likely to affect firms' collaborative behaviour and therefore to confound the effect of the French cluster policy. We generated a dummy variable specifying whether or not an establishment has participated to a project under the Framework Programme during the post-policy period $(2008-2010)^{\mathrm{x}}$ :

$$
F P_{i, t=1}=\left\{\begin{array}{c}
\text { Yes, } \quad \text { if establishment's firm participate in } F P \\
\text { No, otherwise }
\end{array}\right.
$$

We extended our response model from Equation [10] to take into account establishments' collaborative behaviour before joining clusters and their participation to Framework Programme during the treatment period.

To sum up, in our econometric specification, we combine IPTW with the double-difference approach; by doing this we are able to identify the treatment effects in a selection on observables and unobservables context (Imbens and Wooldridge, 2009). Such a specification relies on two main identification assumptions. On the one hand, we assume that the establishment's treatment only affects its behaviour, not that of other establishments; this assumption is known as the Stable Unit Treatment Value Assumption (SUTVA). On the other hand, our specification relies on the Parallel Trend Assumption 
which requires that in the absence of treatment, the difference between cluster members and non-cluster members is constant over time.

The treatment effect is estimated using weighted least squares regressions and heteroskedasticity robust standard errors. We provide for the first time a counterfactual assessment of both collaboration and network behaviour additionality.

\subsection{Robustness check: doubly robust estimation}

A mis-specified propensity model may lead to a wrong estimator for $\delta_{A T T}$. For an estimator of average treatment effect, double robustness means that the estimator remains consistent if either the propensity score model or the outcome regression model is wrong (but not both). Doubly robust propensity score methods rely on dual modelling of both the treatment assignment mechanism and the response to provide unbiased estimates if either the propensity score model or the outcome model is correct (Imbens and Wooldridge, 2009). Although several doubly robust estimators have been proposed (e.g. Bang and Robins, 2005; Kang and Schafer, 2007), the estimate for the average treatment effects can be formulated as follows:

$$
\widehat{\delta_{D R}}=n^{-1} \sum_{i=1}^{n}\left[\frac{Z_{i} \Delta Y_{i}}{e\left(X_{i}\right)}-\frac{Z_{i}-e\left(X_{i}\right)}{e\left(X_{i}\right)} m_{1}\left(X_{i}\right)\right]-n^{-1} \sum_{i=1}^{n}\left[\frac{\left(1-Z_{i}\right) \Delta Y_{i}}{1-e\left(X_{i}\right)}-\frac{Z_{i}-e\left(X_{i}\right)}{1-e\left(X_{i}\right)} m_{0}\left(X_{i}\right)\right]
$$

where $m_{1}\left(X_{i}\right)$ and $m_{0}\left(X_{i}\right)$ are respectively postulated models for the true regressions $E(\Delta Y \mid Z=1, X)$ and $E(\Delta Y \mid Z=0, X)$. This estimator may be viewed as taking each term from the inverse weighted estimator and "augmenting" it by a second term, hence the name "augmented inverse propensity weighted" (AIPW), which is often given to doubly robust estimation in IPTW analyses. Following Bang and Robins (2005) and Kang and Schafer (2007), our double robust estimation consists of a regression estimation of propensity score weighted means using the propensity score as covariates, followed by an estimation of the difference between weighted means with Equation [9]. For an introduction to AIPW estimation see Glynn and Quinn (2010).

In our application of doubly robust estimation with propensity score as covariates, postulated models $m_{1}\left(X_{i}\right)$ and $m_{0}\left(X_{i}\right)$ are based on the recommendation from Bang and Robins (2005), which suggests adding to the regressions the inverse of the propensity score and the inverse of " 1 minus the propensity 
score". Therefore, $m_{1}\left(X_{i}\right)$ and $m_{0}\left(X_{i}\right)$ are fitted to the outcomes of treated and control establishments using:

$$
\begin{aligned}
& m_{1}\left(X_{i}\right)=\Delta Y_{i(Z=1)}=\beta_{0}+\beta_{1} \frac{1}{e\left(X_{i(Z=1)}\right)}+\beta_{2} \frac{1}{1-e\left(X_{i(Z=1)}\right)} \\
& m_{0}\left(X_{i}\right)=\Delta Y_{i(Z=0)}=\beta_{0}+\beta_{1} \frac{1}{e\left(X_{i(Z=0))}\right)}+\beta_{2} \frac{1}{1-e\left(X_{i(Z=0)}\right)}
\end{aligned}
$$

Since the propensity scores are known for the entire sample, the above regressions are used to obtain predicted values $\Delta \widehat{Y_{l(Z=1)}}$ and $\Delta \widehat{Y_{l(Z=0)}}$ but only for treated establishments, since the estimate of interest is the ATT. The doubly robust estimator of the ATT is obtained with Equation [9] using predicted outcomes $\Delta \widehat{Y_{l(Z=1)}}$ and $\Delta \widehat{Y_{l(Z=0)}}$ instead of observed outcomes $\Delta Y_{i(Z=1)}$ and $\Delta Y_{i(Z=0)}$, respectively.

\subsection{Sensitivity analysis}

In the field of causal inference, sensitivity analysis generally refers to approaches that assess the sensitivity of causal estimates to the presence of unmeasured confounders. This is sometimes referred to as sensitivity to "unmeasured confounding" or to "hidden bias" (Rosenbaum, 2002). Sensitivity analyses aim to address a lack of confidence in the assumption, commonly invoked with observational data, that all confounders have been measured (Carnegie et al., 2016). In this vein, the objective of our sensitivity analysis is to identify how much unmeasured confounding would produce a change in the conclusion of the study.

We rely on a method developed by Carnegie et al. (2016) for sensitivity analysis where the relationship between a single confounding variable $U$, treatment $Z$ and outcome $\Delta Y$ are manipulated through a simulation to identify how large these relationships need to be for the treatment to become nonsignificant. This method consists in evaluating changes to the treatment effect and its $p$-value for a set of values of two sensitivity parameters.

Let us denote $\zeta^{Z}$ as the sensitivity parameter quantifying the relationship between $U$ and $Z$, while $\zeta^{\Delta \mathrm{Y}}$ quantifies the relationship between $U$ and $\Delta Y$. This method is a five-step process implemented as follows (Leite, 2016): 
1. Define sensitivity parameters based on the observed data. Multiple values should be selected for both $\zeta^{Z}$ and $\zeta^{\Delta Y}$, which results in a matrix of combinations of values.

2. For each pair of values of $\zeta^{Z}$ and $\zeta^{\Delta Y}$ and the vector of observed values of $\Delta Y, Z$, and $X$, simulate $U$ from the conditional distribution of $U$ given $\Delta Y, Z$, and $X$.

3. Fit the response model with $Z, X$, and $U$ as predictors and obtain the treatment effect and its standard error.

4. Repeat Steps 2 and 3 for $k$ iterations with the same pair of sensitivity parameters, and average the treatment effects across iterations. The standard error is obtained by squaring the sum of the within-replication and between-replication variances.

5. Select another pair of sensitivity parameters and repeat Steps 2 to 4.

In our implementation of this method, the response model is fitted the same way as in the doubly robust estimation i.e., with the inverse of the propensity score and the inverse of " 1 minus the propensity score" as covariates. Changes in treatment effects, given the coefficients on $U$, are shown in Table 7 in the Appendix. The coefficients on the confounding variable $U$ reflect the strength of the relationships between $U$ and the treatment $Z$ on the one hand, and between $U$ and the outcome $\Delta Y$ on the other. Therefore, conclusions from the sensitivity analysis result from an evaluation of the coefficients on the confounding variable compared to the estimated coefficients obtained from the regression of $\Delta Y$ on $Z$ and $X$ and from the regression of $Z$ on $X$.

\section{Empirical results}

\subsection{Propensity score results and balancing the sample}

As explained in Section 5, the objective of IPTW analyses is to first create a weighted sample in which the distribution of the confounding variables is the same between treated and control groups. In our analysis, propensity scores resulting from the simple specification i.e., the probit regression, achieved the best balance in baseline covariates (see Table 6 in the Appendix). Therefore, the results presented in this section are based on that model. 
Before presenting the treatment effect results, let us start by analysing the results of the probit regression estimating the treatment assignment. Table 2 shows the coefficients and marginal effects of the probit estimation to derive the propensity score for being a cluster member. The general conclusion of this model is that results are in line with previous findings about firms' participation in clusters.

First, the size of the establishment is positively correlated to joining a cluster. This is not a surprising relationship, since larger establishments are likely to have more resources, especially human resources, dedicated to R\&D activities and they are, therefore, likely to be among the most active organisations doing research. Bellego and V. Dortet-Bernadet (2014) also found the same relation when estimating the probabilities of firms joining French clusters. This relationship is complemented with a positive marginal effect of the establishment's share of highly-qualified employees. Beyond the fact that the larger establishments tend to join clusters, establishments with highly-qualified employees are also likely to join clusters. However, this relationship is limited by a negative quadratic effect of highlyqualified employment on the probability of being cluster member.

Results of the propensity score model also reveal that establishments of micro-enterprises, and smalland medium-sized enterprises (SMEs) were more likely to join clusters than large firms' establishments. This finding is in line with the rationale behind the French cluster policy, which tends to provide much greater support to establishments that have greater difficulty innovating. Typically, the subsidy rate for collaborative $\mathrm{R} \& \mathrm{D}$ projects which are supported by a French cluster is always higher for SMEs than for large companies. Furthermore, public statistics on the composition of French clusters show that they are mainly composed of SMEs ${ }^{\mathrm{xi}}$.

A sectorial effect can be observed in joining clusters. The propensity score model indicates that establishments in high-technology industries were more likely to join clusters. Ben Hassine and Mathieu (2017) also found the same result when estimating the probabilities of firms joining French clusters. Indeed, this result is strongly in line with the aim of the French cluster policy, which is to mainly support industrial activities with a significant technological component. 
Table 2. Propensity score model (simple specification)

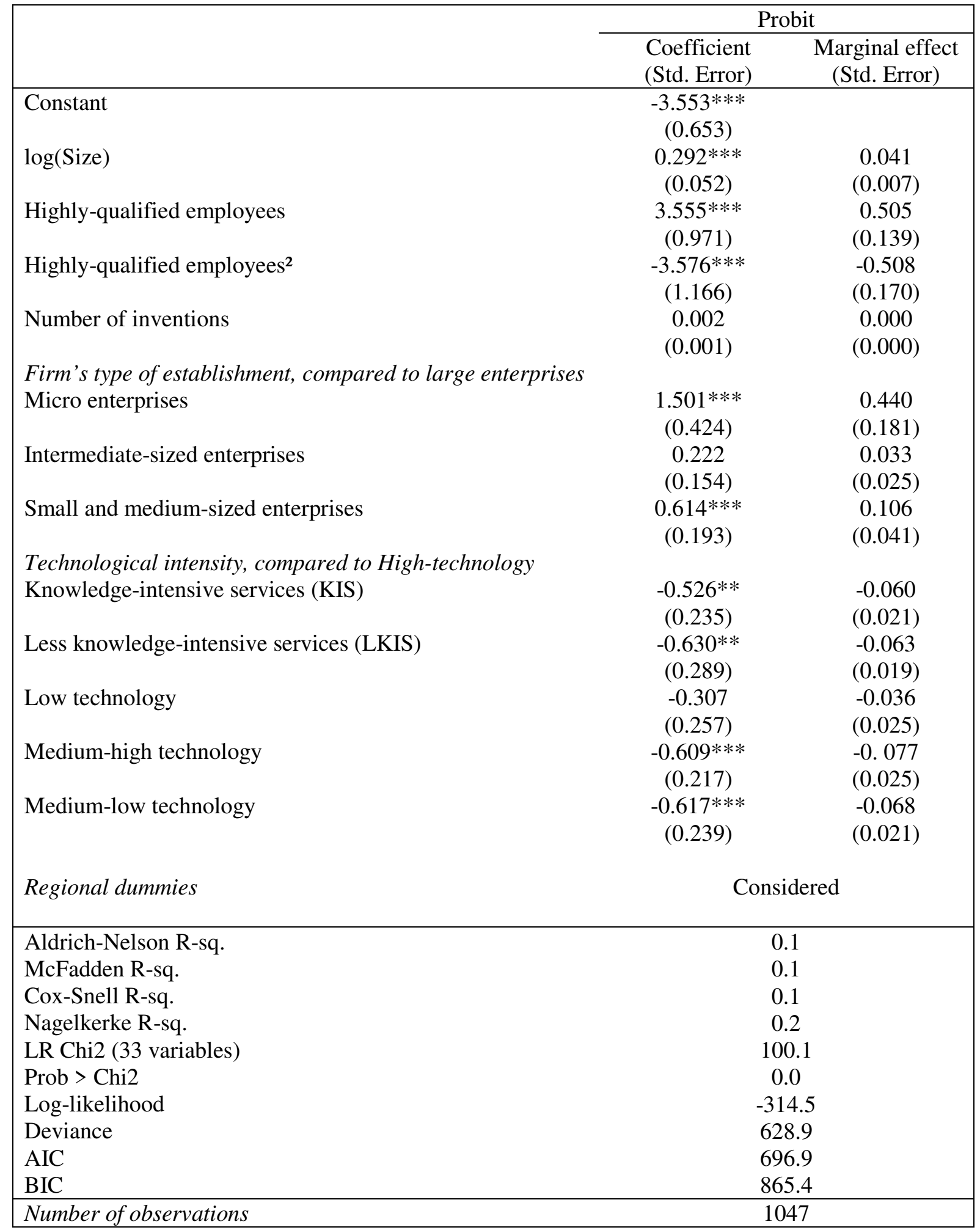

Note: Statistical significance: ${ }^{*} \mathrm{p}<0.10,{ }^{* *} \mathrm{p}<0.05, * * * \mathrm{p}<0.01$ 
We found no evidence that the number of inventions is a determining factor for an establishment to join a cluster. This could seem counterintuitive, since Table 1 clearly shows the gap between treated subjects and controls regarding their number of inventions. Our view on this is that the number of inventions can be perceived as an output of establishments' R\&D activities. In this vein, after controlling for factors such as the size of establishments or their sector, we end up by neutralising a potential effect of the number of inventions on the probability of joining clusters. This variable is, however, retained in the propensity score model since, otherwise, the propensity score model would not allow to balance the "number of inventions" between the treated and the controls.

As shown in Insert Figure 1, our weighting process based on propensity scores from the probit model (simple specification) considerably improves balance in the sample. Even though the nonparametric generalised boosted model failed to balance the treated and controls as regards "Region", it performs fairly well and its resulting propensity scores and those obtained with the probit regression are highly correlated $(>90 \%)$. This is an indication of the relevance and reliability of the simple specification of the propensity score model.

\section{Insert Figure 1 here}

\subsection{Effect of French clusters and discussion}

Table 3 shows that cluster members exhibit, on average, an increase of about 0.034 i.e., 3.4 percentage points, in their co-invention rate. After controlling for participation in the Framework Programme and the pre-policy behaviour of establishments towards collaboration, the effects of cluster membership on establishments' co-invention rate rises to 0.041 i.e., 4.1 percentage points. This indicates a positive and significant effect of the French cluster policy on the co-invention rate of cluster members and therefore on their collaborative behaviour. This result provides evidence for a behavioural additionality effect of the French cluster policy and therefore confirms the positive impact of the clusters, since they have been able to encourage their members to become more involved in collaborative R\&D projects . In a context where cluster policies are often criticised regarding their input and output additionality (Vicente, 2014; Duranton, 2011), this result supports the ability of clusters to influence collaborative behaviour. 
Table 3. Effects on collaboration and intra-regional collaboration

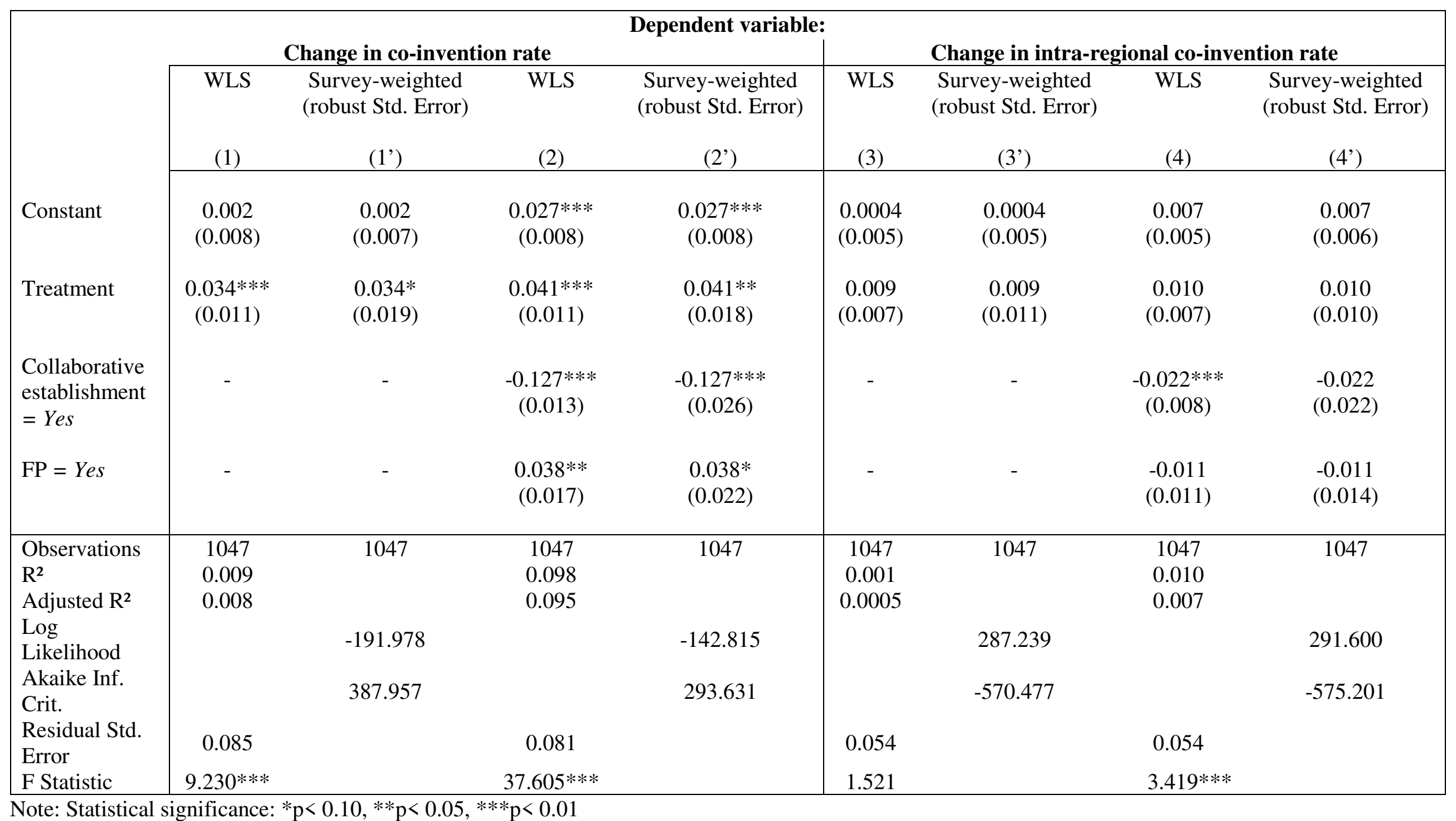


Compared to previous studies, we thus confirm for the French case positive findings obtained on other contexts by Nishimura and Okamuro (2011) for Japanese clusters, by Afcha Chavez (2011) or by several studies focusing on regional supports to R\&D collaboration (Afcha Chavez, 2011 in Spain ; Tierlink and Spitoven, 2012 in Belgium and Caloffi et al., 2018 in Italy). In addition to these studies, our results suggest that the policy may increase collaboration even beyond the only financial incentives since the participation in co-inventions encompasses non subsidised projects.

The robustness of the significant effect on the co-invention rate is tested using a doubly robust estimation procedure. The doubly robust estimate of the average treatment effect is 0.041636 , with a standard error of 0.0175 . This estimate is close to that obtained previously with a non-doubly robust estimator (Table 3). This is a desirable result because it shows that the effect is not sensitive to the specification of the response model. Moreover, the sensitivity analysis reveals that our result is not highly sensitive to the presence of unmeasured confounders since the current effect would change only if a confounder with a strong relationship with $Z$ or $\Delta Y$ (especially on $\Delta Y$ ) were included in the analysis (Table 7). Indeed, the sensitivity analysis indicates that even in the presence of an unmeasured confounder which explains up to $10 \%$ of the variation of $\Delta Y$ (but which does not affect $Z$ ), the estimate of the average treatment effect would remain almost constant and significant. It is also worth noting that the estimated average treatment effect is not only due to the increase in the co-invention rate of some treated subjects, especially those already engaged in co-inventions before joining clusters. It also results from an increase in the number of treated establishments engaged in co-inventions (from 32 during the pre-treatment period to 41 during the post-treatment period; and 23 treated subjects which were engaged in co-inventions during both periods). Furthermore, this effect is not exclusively the result of an increase in co-inventions between cluster members alone. During the post-treatment period, $17 \%$ of cluster members were engaged in coinventions with other cluster members and $9.3 \%$ of non-cluster members were also engaged in coinventions with cluster members.

Regarding the control variables, we observed a positive and significant relationship between participation in the Framework Programme projects and establishments' co-invention rate. As expected, this provides evidence as to the role of the EU Framework Programme in affecting firms' collaborative 
behaviour through the support of collaborative R\&D projects between organisations across Europe. Interestingly, we observe a negative and significant correlation between the collaborative behaviour of establishments before joining clusters and the change in their co-invention rate. Establishments which were already engaged in collaborative $\mathrm{R} \& \mathrm{D}$ projects before joining clusters tend to increase their coinvention rate to a smaller extent compared to establishments with little or no prior experience in collaboration. This unexpected result suggests that the positive average effect on the co-invention rate might hide some heterogeneity between establishments depending on their willingness to collaborate. We will have more to say on that in the next sub-section.

As discussed above, cluster membership has a positive and significant effect on establishments' coinvention rate. However, we observed no significant effect on the intra-regional collaboration. This suggests that although clusters have effectively supported their members in participating in collaborative projects, a very small proportion of these collaborations involve organisations from the region to which cluster members belong. While recent literature on geography of innovation suggests that interregional collaborations should not be supported at the expense of intraregional collaborations (De Noni et al., 2017), our results reveal that the French cluster policy has not significantly strengthened the establishment of collaborations between organisations located in the same region. This result could be explained by the fact that the studied period partially covers the second phase of the cluster policy (20092012) during which interregional collaborations were encouraged. It would seem that the strengthening of interregional collaborations has been to the detriment of intra-regional collaborations. This could be damaging for innovation, since collaborations with proximate partners are those who favours most the innovative output (Hazir and Autant-Bernard, 2016). 
Table 4. Effects on network embeddedness

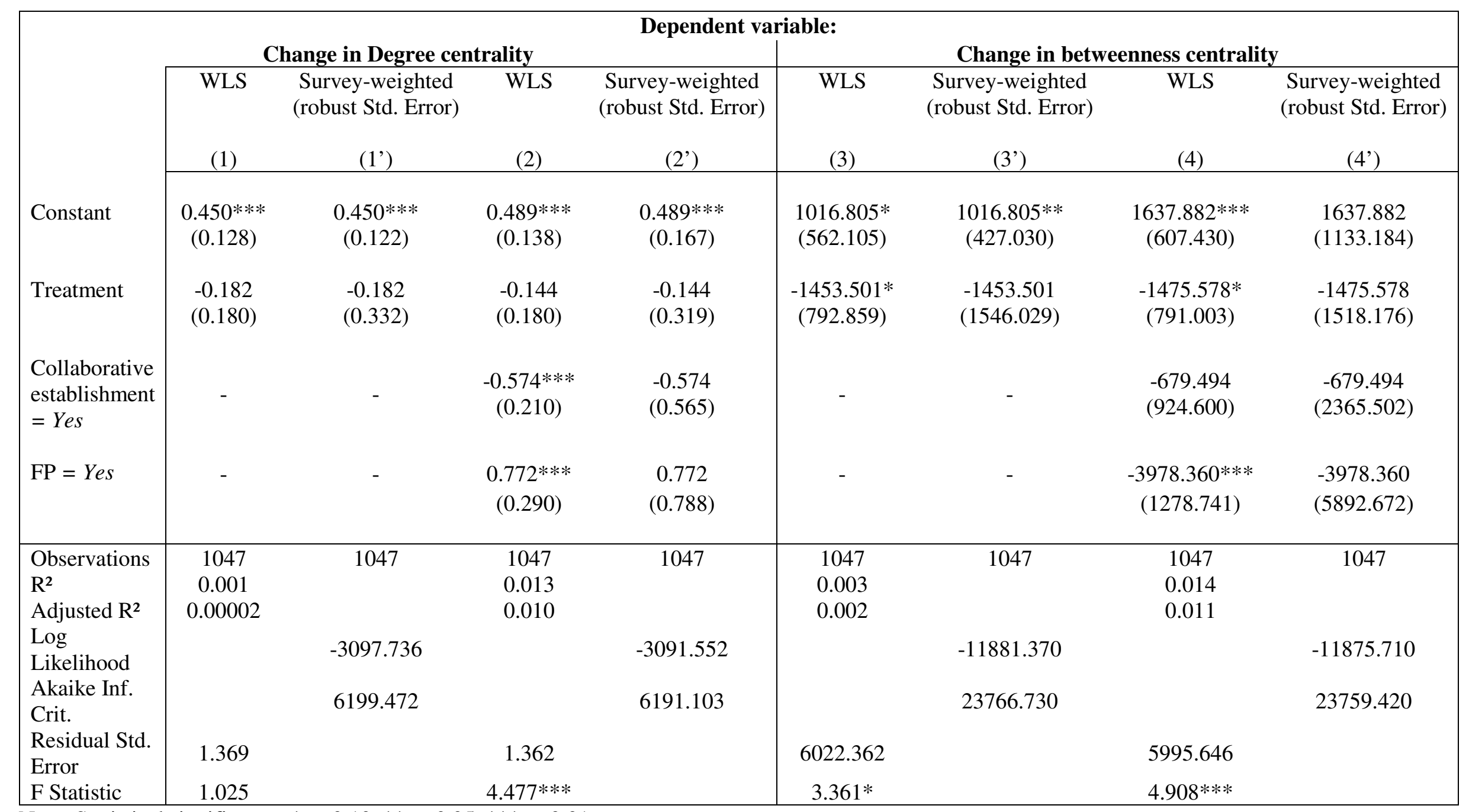

Note: Statistical significance: ${ }^{*} \mathrm{p}<0.10,{ }^{* *} \mathrm{p}<0.05,{ }^{* * *} \mathrm{p}<0.01$ 
Furthermore, we observed no significant effect on network embeddedness variables, namely the degree centrality and the betweenness centrality (Table 4). To this regard, our results differ from past studies on cluster policies which tend to conclude on the improvement of the network properties. Giuliani et al. (2016), evaluating a cluster development programs in the electronics cluster in Argentina observe a reduction in the number of isolated firms together with a higher polarisation and centralisation of the network. In the French context, Delio and Vicente (2019) find that the structure of the Aerospace Valley cluster has moved from a highly-hierarchical structure, centralised around a couple of long-established oligopolistic companies, to a more democratic, less assortative, and multipolar structure, involving the entry of SMEs to the elite part of the network. However, these past studies do not control for confounding factors as they focus on the network of treated units only. Using for the first time a counterfactual analysis to evaluate cluster policies, and moving from case studies to systematic analysis of a National cluster programme, our findings suggest that the change in the network structure over time results more from a global dynamic of collaborative R\&D networks than from the specific incentives induced by cluster policies

There are several possible interpretations for this result. The French cluster policy failed to strengthen the embeddedness of cluster members into networks of co-inventions. Broekel et al. (2015) found a similar result on embeddedness while using data from subsidised $R \& D$ projects. Their results suggest that firms in clusters tend to be less intensively embedded in nationally subsidised networks of R\&D collaboration. Our results show that cluster membership does not increase establishments' embeddedness into collaboration networks. Since we previously found a positive and significant effect of cluster membership on the co-invention rate (Table 3), this insignificant effect on network embeddedness could be explained by the fact that cluster members collaborate with almost the same partners in their different projects. However, an analysis over a longer period of time would be necessary to validate this hypothesis. Another interpretation might be found in the interaction between cluster and FP policies. It might be the case that the cluster members which face an increase in their centrality are those who participate in FP. As such, the French cluster would produce an indirect effect on centrality by encouraging FP participation. This indirect effect goes beyond the scope of this paper, but it would 
represent an interesting avenue for further research. The absence of a centrality effect may also result from a strong heterogeneity of the cluster policy effect on network positioning of innovating firms. This is investigated more thoroughly in the next sub-section. Finally, the French cluster policy may also increase the size of the network, allowing new actors to enter the invention network. The centrality of historical actors could therefore be reduced. This interpretation is in line with our previous result, pointing to a higher impact on collaborations for those firms which were not involved in co-inventions before their cluster participation. In any case, our results corroborate those obtained by Broekel et al. (2015) for spontaneous clusters, in showing that the effects of cluster membership on organisations' embeddedness in collaboration networks are not systematic.

\subsection{Treatment heterogeneity}

There are good reasons to believe that the positive average effect on the co-invention rate might hide some heterogeneity between establishments depending on their pre-policy behaviour towards collaboration. Such an heterogeneity has already been highlighted in few previous studies on collaboration-based policies (Afcha Chávez, 2011; Teirlinck and Spithoven, 2012). In our case, following the negative effect of the pre-policy period collaborative behaviour of an establishment (Table 3), one would expect a different effect on establishments which were engaged in collaborations and establishments with little or no experience in collaboration before joining clusters. To test for such a heterogeneous treatment effect, we estimated the response models stratified by the pre-policy behaviour of establishments towards collaboration (collaborative establishment) and formally tested for effect heterogeneity (Table 5). The same analysis was also run for the local collaboration rate and our two measures of centrality. However, these measures do not provide any significant coefficient. Only the co-invention rate results are therefore reported in Table 5. The results obtained for the other dependent variables are available upon request.

In addition to the positive effect of cluster membership on the co-invention rate initially observed (Table 3), Table 5 indicates that this increase is much higher for cluster members which were weakly involved in collaborative R\&D projects before joining the clusters. Those establishments have increased their coinvention rate by more than 6 percentage points as a result of being cluster members, while the effect of 
cluster membership becomes insignificant for cluster members which were engaged in collaborations before joining clusters. Although still confirming the positive impact of French clusters in improving the collaborative behaviour of organisations, this result reveals that this impact is more likely to be on establishments with little or no experience in collaboration before joining clusters. The absence of significant effect observed on establishments which were already engaged in collaborations before joining clusters may suggest that those establishments do not necessarily join clusters with the goal to expanding their network of partners. They are more likely to be interested in other cluster premiums such as the access to R\&D subsidies (Broekel et al., 2015).

Table 5. Treatment heterogeneity

\begin{tabular}{|c|c|c|}
\hline \multicolumn{3}{|c|}{ Change in co-invention rate } \\
\hline \multirow{4}{*}{ Constant } & WLS & $\begin{array}{l}\text { Survey-weighted } \\
\text { (robust Std. Error) }\end{array}$ \\
\hline & (1) & $\left(1^{\prime}\right)$ \\
\hline & 0.0003 & 0.0003 \\
\hline & $(0.008)$ & $(0.007)$ \\
\hline $\mathrm{FP}=Y e s$ & $\begin{array}{c}0.016 \\
(0.018)\end{array}$ & $\begin{array}{c}0.016 \\
(0.022)\end{array}$ \\
\hline $\begin{array}{l}\text { Treatment } \times \text { Collaborative } \\
\text { establishment }=N o\end{array}$ & $\begin{array}{l}0.063 * * * \\
(0.012)\end{array}$ & $\begin{array}{c}0.063 * * * \\
(0.020)\end{array}$ \\
\hline $\begin{array}{l}\text { Treatment } \times \text { Collaborative } \\
\text { establishment }=\text { Yes }\end{array}$ & $\begin{array}{c}-0.042 * * \\
(0.017)\end{array}$ & $\begin{array}{c}-0.042 \\
(0.041)\end{array}$ \\
\hline Observations & 1047 & 1047 \\
\hline $\mathrm{R}^{2}$ & 0.042 & \\
\hline Adjusted $\mathrm{R}^{2}$ & 0.039 & \\
\hline Log Likelihood & & -174.130 \\
\hline Akaike Inf. Crit. & & 356.259 \\
\hline Residual Std. Error & 0.084 & \\
\hline F Statistic & $15.235 * * *$ & \\
\hline
\end{tabular}

Note: Statistical significance: $* \mathrm{p}<0.10, * * \mathrm{p}<0.05, * * * \mathrm{p}<0.01$. We also tested for effect heterogeneity for the other outcome variables, namely intra-regional co-invention rate, degree centrality and betweenness centrality; we still did not observe any significant treatment effects. 


\section{Conclusion}

This article aimed to investigate the extent to which cluster policies favour collaboration and induce network additionality. Focusing on the French national cluster policy and on the collaborative behaviour of cluster members during the period 2008-2010, the aims were threefold: H1) to assess whether cluster members are more engaged in co-inventions, and especially, H2) with co-located organisations and H3) to assess whether cluster members are more embedded in networks of co-inventions. We combined the Inverse Probability of Treatment Weighting (IPTW) with a difference-in-difference estimator in order to address the causal effects of cluster membership on firms' establishments. Though the results remain somehow specific to the French context, this policy is among the most intensive one in the world, France being the country which devotes the highest budget in Europe to a National cluster programme. We can therefore believe that this policy provides a relevant field experiment to assess the potential impacts of national cluster policies. Our empirical findings confirm that such policies can significantly enable their members to be more engaged in co-inventions: on average, French cluster members increased their coinvention rate by 4.1 percentage points as a result of their membership. Notably, the policy had a greater impact upon establishments with little or no experience in collaboration before joining clusters, leading to an increase in their co-invention rate of 6.3 percentage points. However, we found no evidence that cluster members were more engaged in co-inventions involving co-located partners, implying that the French cluster policy failed to reinforce intra-regional collaboration. Regarding the embeddedness of cluster members in networks of co-inventions, we also find no evidence for any significant effect of the cluster policy. In summary, we confirmed hypothesis H1, but failed to confirm hypotheses H2 and H3. This suggests, on the one hand, that cluster members, especially those with little or no prior experience in collaborations, have become more open to collaboration but not necessarily with regional actors. On the other hand, cluster members did not show a stronger embeddedness into networks of co-inventions than non-members, either quantitatively (by increasing the number of direct partners) or qualitatively (by acting more as "bridge" between other establishments). French clusters were thus able to tackle network failures during the studied period, but only partially. 
We therefore confirm the results obtained for other collaboration-based policies (regional support to R\&D collaboration) in various countries regarding the ability of public incentives to generate collaboration additionality (Afcha Chavez, 2011; Nishimura and Okamuro, 2011; Caloffi et al, 2018, 2011). We add to these previous results in providing specific insights regarding the lack of local impact (H2) of cluster policies, at least in France. And more importantly, we call into question the conclusions of previous studies regarding the ability of cluster policies to improve the overall structure of collaborative R\&D networks (H3). This criticism of past results relies on the mobilisation of a counterfactual sample, allowing a better identification of the causal relationships between the public incentives to R\&D collaboration and the evolution of network properties over time.

Therefore, whereas the actors' positions within networks have been proved to be strongly correlated to the actors' level of performance, the various types of services provided by clusters to favour network embeddedness do not necessarily contribute to this goal. Clusters are not sufficient tools, at least in the short run, to improve the ability of actors to identify relevant networks, or conversely to raise awareness of local industrial specialisms in order to make local firms more likely to be asked to enter national and international partnerships and therefore to increase their centrality within knowledge networks. Our results may also suggest, following Martin and Sundley (2003), that more attention should be devoted to identifying and attracting investors and businesses likely to fill the gaps in existing cluster value chains in order to strengthen the network positioning of local anchor firms by reinforcing their demand and supply links. Nevertheless, it should be noted that our findings do not call into question the relevance of clusters for firm growth and regional development. Indeed, clusters may still be important factors in achieving these goals but not necessarily through the intensification of collaborations between regional actors. By supporting long-distance collaboration which is also required to improve regional innovation capacity (Boschma, 2005), clusters continue to contribute to regional development. They can also contribute to the growth of firms through training activities for skills development (Giuliani et al., 2016).

The main point of this study is that the local anchoring of clusters i.e., their ability to reinforce links between co-located organisations, as well as the embeddedness of cluster members in collaboration networks is not systematic. This claim has a number of policy implications that especially concern the 
design and evaluation of cluster policies. It first raises the question of the theoretical framework in which cluster policies are designed and the extent to which such policies differ from other policy instruments supporting innovation. Although it is widely accepted that collaboration-based innovation policies, especially cluster policies, not only deal with market failures but also with systemic failures (Uyarra and Ramlogan, 2012), the evaluation of cluster policies is still largely focused on their contribution towards tackling market failures. We argue that the lack of studies focusing on the impact of cluster policies from a systemic failures perspective is often due to the lack of a clear theory-based design of such policies regarding the systemic failures they are supposed to tackle. Our results highlight the importance for policymakers of clearly defining the network failures and, more broadly the systemic failures they want to tackle while designing cluster policies. Otherwise, it would be difficult to assess the impacts of clusters beyond input and output additionality. When systemic failures can be assessed, they highlight the structural effects of cluster policies. For instance, our study stresses that cluster policies do not necessarily strengthen local collaborations. Policymakers should therefore be careful not to encourage long-distance collaborations to the detriment of local ones, given the complementary roles of both forms of collaboration (De Noni et al., 2017). They should also encourage cluster actors to become more embedded in collaboration networks and to go beyond simple bilateral collaborations with the same partners. Such incentives could take the form of a stronger support to cluster members to find new local, national or foreign partners. As pointed out previously by Vicente (2014), it is clear that new opportunities for cluster policies exist through surgical incentives for $\mathrm{R} \& \mathrm{D}$ collaborations tackling network failures.

Despite the above findings, our study has some shortcomings which also open avenues for future research. First, our results relate to a relatively short period and therefore should be corroborated by further empirical analyses over a longer period. Such analyses could also be based on collaboration data collected directly from establishments or firms, although this may be a resource-intensive methodological exercise. However, this would be all the more relevant since collaborative R\&D projects do not necessarily lead to co-patenting and given the importance of informal collaboration in R\&D activities. Future research may also extend our study by exploring further structural effects of cluster 
policies, such as science-industry collaborations, since they are increasingly perceived as a means of enhancing knowledge transfers from research institutions to industry. Finally, it should be noted that the analyses carried out in this paper lead to aggregated results that do not necessarily reflect the situation in each (French) cluster individually. Although this study makes it possible to draw overall conclusions, essentially based on average effects, a more detailed analysis of each cluster - involving qualitative methods - could reveal some differences.

\section{Acknowledgements}

This work was supported by the French National Research Agency [ANR14-CE29-0005-01]; and the Auvergne-Rhône Alpes Regional Council [SCUSI-1700937101]. 


\section{References}

Abdia, Y., Kulasekera, K., Datta, S., Boakye, M., Kong, M., 2017. Propensity Scores Based Methods for Estimating Average Treatment Effect and Average Treatment Effect Among Treated: A Comparative Study. Biometrical Journal, 967-985.

Afcha Chávez, S. M., 2011. Behavioural additionality in the context of regional innovation policy in Spain. Innovation, 13(1), 95-110.

Antonioli, D., Marzucchi, A., \& Montresor, S., 2014. Regional innovation policy and innovative behaviour: looking for additional effects. European Planning Studies, 22(1), 64-83.

Austin, P., Stuart E., 2015. Moving towards best practice when using inverse probability of treatment weighting (IPTW) using the propensity score to estimate causal treatment effects in observational studies. Statistics in Medicine, 34, 3661-79.

Baccaïni, B., Sémécurbe, F., Thomas, G., 2007. Les déplacements domicile-travail amplifiés par la périurbanisation. National Institute of Statistics and Economic Studies.

Bang, H., Robins, J. M., 2005. Doubly robust estimation in missing data and causal inference models. Biometrics, 61(4), 962-973.

Bellégo, C., Dortet-Bernadet, V., 2014. L'impact de la participation aux pôles de compétitivité sur les PME et les ETI. Économie et Statistique, 471, 65-83.

Ben Hassine, H., Mathieu, C., 2017. Évaluation de la politique des pôles de compétitivité : la fin d'une malédiction ?, France Stratégie.

Bleda, M., \& Del Rio, P., 2013. The market failure and the systemic failure rationales in technological innovation systems. Research policy, 42(5), 1039-1052.

Blomkvist, K., Kappen P., Zander, I., 2014. Superstar inventors—towards a people-centric perspective on the geography of technological renewal in the multinational corporation. Research Policy 43 (4), 669-682.

Boschma, R., 2005. Proximity and innovation. A critical assessment, Regional Studies, 39 (1), 61-74. 
Branstetter, L. G., \& Sakakibara, M., 2002. When do research consortia work well and why? Evidence from Japanese panel data. American Economic Review, 92(1), 143-159.

Broekel, T., Fornahl, D., \& Morrison, A. (2015). Another cluster premium: Innovation subsidies and R\&D collaboration networks. Research policy, 44(8), 1431-1444.

Calignano, G., \& Fitjar, R. D., 2017. Strengthening relationships in clusters: How effective is an indirect policy measure carried out in a peripheral technology district? The Annals of Regional Science, 59(1), 139-169.

Caloffi, A., Rossi, F., \& Russo, M., 2015. What makes SMEs more likely to collaborate? Analysing the role of regional innovation policy. European Planning Studies, 23(7), 1245-1264.

Caloffi, A., Mariani, M., Rossi, F., Russo, M., 2018. A comparative evaluation of regional subsidies for collaborative and individual R\&D in small and medium-sized enterprises. Research Policy 47 (8), $1437-1447$

Carnegie, N., Harada, M., Hill, J., 2016. Assessing sensitivity to unmeasured confounding using a simulated potential confounder. Journal of Research on Educational Effectiveness, 9(3), 395-420.

Coase, R.H., 1960. The Problem of Social Cost, Journal of Law and Economics, 3 (October 1960), 144.

Coudène, M., Levy, D., 2016. De plus en plus de personnes travaillent en dehors de leur commune de résidence. National Institute of Statistics and Economic Studies.

Criscuolo, C., J. Haskel, 2003. Innovation and Productivity Growth in the UK: Evidence from CIS2 and CIS3, Working paper, Center for Research into Business Activity.

D'Aspremont, C. and Jacquemin, A., 1988. Cooperative and Non-cooperative R\&D in Duopoly with Spillovers, American Economic Review, 78 (5), 1133-1137.

De Noni, I., Ganzaroli, A. and Orsi, L., 2017. The impact of intra-and inter-regional knowledge collaboration and technological variety on the knowledge productivity of European regions. Technological Forecast. Social. Change 117, 108-118. 
Dehejia, R.H., Wahba, S., 1999. Causal effects in nonexperimental studies: Reevaluating the evaluation of training programs. Journal of the American Statistical Association, 94, 1053-1062.

Directorate General for Enterprise - DGE, 2017. Competitiveness clusters. Etudes et statistiques, 4 pages $n^{\circ} 67$.

Duranton, G., 2011, California Dreamin': The Feeble Case for Cluster Policies. Review of Economic Analysis 3: 3-45.

European observatory for cluster and industrial change, 2019. Report: Cluster programmes in Europe and beyond, European Union, pp. 146.

European Patent Office, 2011. Patent teaching kit. Available at: https://ecourses.epo.org/pluginfile.php/1428/mod_resource/content/1/data/Patent_teaching_kit_screen.p df [Accessed September 7, 2018].

Everett, M. G., \& Valente, T. W. (2016). Bridging, brokerage and betweenness. Social networks, 44, 202-208.

Falck, O., S. Heblich, and S. Kipar. 2010. Industrial Innovation: Direct evidence From a ClusterOriented Policy. Regional Science and Urban Economics 40 (6), 574-582.

Fontagné, L., Koenig, P., Mayneris, F., Pocet, S., 2013. Cluster policies and firm selection: Evidence from France, Journal of Regional Science, 53(5), 897-922.

Freeman, C., 1987. Technology policy and economic performance: Lessons from Japan, Pinter Publishers, London.

Giuliani, E., Matta, A., Pietrobelli, C., 2016. Networks, Cluster Development Programs, and Performance: The Electronics Cluster in Córdoba, Argentina, in: Stucchi, R., 2016. The Impact Evaluation of Cluster Development Programs: Methods and Practices. Inter-American Development Bank, 117-150.

Glynn, A., Quinn, K., 2010. An Introduction to the Augmented Inverse Propensity Weighted Estimator. Political Analysis 18(1), 36-56. 
Hazır, C. S., LeSage, J., \& Autant-Bernard, C. 2018. The role of R\&D collaboration networks on regional knowledge creation: Evidence from information and communication technologies. Papers in Regional Science, 97(3), 549-567.

Hinloopen, J., 2001. Subsidizing R\&d Cooperatives. De economist, 149(3), 313-345.

Imbens, G. W., 2004. Nonparameteric estimation of average treatment effects under exogeneity : a review. The Review of Economics and Statistics 86, 4-29.

Imbens, G. W., and Wooldridge, J. M., 2009. Recent developments in the econometrics of program evaluation. Journal of Economic Literature 47(1), 5-86.

Janz, N., Lööf H., B. Peeters, 2003. Firm Level Innovation and Productivity - is There a Common Story Across Countries? ZEW Working Paper No. 2003-26, Mannheim, Germany.

Kang, J., Schafer, J., 2007. Demystifying double robustness: A comparison of alternative strategies for estimating a population mean from incomplete data. Statistical Science, 22(4), 523-539.

Krugman, P., 1991. Geography and trade, Leuven University Press, Leuven.

Leite, W. L., 2016. Practical propensity score methods using R. Thousand Oaks, CA: Sage.

Lucena-Piquero, D., \& Vicente, J., 2019. The visible hand of cluster policy makers: An analysis of Aerospace Valley (2006-2015) using a place-based network methodology. Research Policy, 48(3), 830-842.

Lundvall, B-Å., 2004. The Economics of Knowledge and Learning, in J.L. Christensen and B.-Å. Lundvall (eds.), Product Innovation, Interactive Learning and Economic Performance (Research on Technological Innovation and Management Policy, volume 8), Amsterdam: Elsevier, 21-42.

Mamdani, M., Sykora, K., Li, P., Normand, S.L., Streiner, D., Austin, P., Rochon, P., Anderson, G., 2005. Reader's guide to critical appraisal of cohort studies: Assessing potential for confounding. British Medical Journal 330 (7497), 960-962.

Marshall, A., 1920. Principles of economics. Macmillan and Co Ltd., London. 
Martin, P., Mayer, T. and Mayneris, F., 2011. Public support to clusters: a firm-level study of French "Local Productive Systems”, Regional Science and Urban Economics, 41, 108-123.

McCaffrey, D., Ridgeway, G., Morral, A., 2004. Propensity score estimation with boosted regression for evaluating causal effects in observational studies. Psychological Methods 9, 403-425.

Nishimura, J., Okamuro, H., 2011. R\&D Productivity and the Organization of Cluster Policy: An Empirical Evaluation of the Industrial Cluster Project in Japan. The Journal of Technology Transfer 36 (2), 117-144.

Normand, S., Landrum, M., Guadagnoli, E., Ayanian, J., Ryan, T., Cleary, P., McNeil, B., 2001. Validating recommendations for coronary angiography following acute myocardial infarction in the elderly: a matched analysis using propensity scores. Journal of Clinical Epidemiology 54(4), $387-398$.

OECD, 2007. Competitive regional clusters: National policy approaches, OECD Reviews of Regional Innovation, pp. 350.

OECD, 2010. Science, Technology and Innovation Outlook, pp. 280.

Olmos, A., Govindasamy, P., 2015. A practical guide for using propensity score weighting in R. Practical Assessment, Research \& Evaluation, 20 (13), 1-8.

Phelps, C., 2010. A longitudinal study of the influence of alliance network structure and composition on firm exploratory innovation. Academy of Management Journal, 53, 890- 913.

Phlippen, S., van der Knaap, B. 2007. When clusters become networks. Tinbergen Institute. Working paper.

Porter, M., 1998. Clusters and the New Economics of Competition. Harv. Bus. Rev.

Rosenbaum, P., 2002. Observational studies. New York, NY: Springer. 
Rossi, F., Caloffi, A., \& Russo, M., 2016. Networked by design: Can policy requirements influence organisations' networking behaviour?. Technological Forecasting and Social Change, 105, 203214.

Rubin, D., 1974. Estimating the Causal Effects of Treatments in Randomized and Non-Randomized Studies, Journal of Educational Psychology 66, 688-701.

Rubin, D., 1978. Bayesian inference for causal effects: The role of randomization. Annals of Statistics $6,34-58$.

Rubin, D., 1980. Discussion of "randomization analysis of experimental data in the Fisher randomization test” by D. Basu. Journal of the American Statistical Association 75, 591-593.

Sakakibara, M., 1997. Evaluating government-sponsored R\&D consortia in Japan: who benefits and how?. Research Policy, 26(4-5), 447-473.

Schafer, J. L., and Kang, J., 2008. Average causal effects from nonrandomized studies: A practical guide and simulated example. Psychological Methods, 13(4), 279-313.

Scherngell, T. and Barber, M.J., 2009. Spatial interaction modelling of cross-region R\&D collaborations. Empirical evidence from the 5th EU Framework Programme, Papers in Regional Science, 88 (3), 531-546.

Scherngell, T., \& Lata, R., 2013. Towards an integrated European Research Area? Findings from Eigenvector spatially filtered spatial interaction models using European Framework Programme data. Papers in Regional Science, 92(3), 555-577.

Stone, C., Tang, Y., 2013. Comparing propensity score methods in balancing covariates and recovering impact in small sample educational program evaluations. Practical Assessment, Research \& Evaluation, 18(13), 1-12.

Technopolis, Erdyn and BearingPoint, 2012. Etude portant sur l'évaluation des pôles de compétitivité, report for DATAR and DGCIS. 
Teirlinck, P., \& Spithoven, A., 2012. Fostering industry-science cooperation through public funding: differences between universities and public research centres. The Journal of Technology Transfer, 37(5), 676-695.

Tomasello, M. V., Napoletano, M., Garas, A., \& Schweitzer, F. (2017). The rise and fall of R\&D networks. Industrial and corporate change, 26(4), 617-646.

Van Leeuwen, G., 2002. Linking Innovation to Productivity Growth Using Two Waves of the Community Innovation Survey, OECD Science, Technology and Industry Working Papers, No. 2002-08, OECD Publishing.

Vicente, J., 2014. Don't Throw the Baby out with the Bath Water: Network Failures and Policy Challenges for Cluster Long Run Dynamics. Papers in Evolutionary Economic Geography, Utrecht: University of Utrecht.

Wanzenböck, I., Scherngell, T., \& Fischer, M. M., 2013. How do firm characteristics affect behavioural additionalities of public R\&D subsidies? Evidence for the Austrian transport sector. Technovation, 33(2-3), 66-77.

Woolthuis, R. K., Lankhuizen, M., \& Gilsing, V., 2005. A system failure framework for innovation policy design. Technovation, 25(6), 609-619.

\section{Funding}

This work was supported by the French National Research Agency [ANR14-CE29-0005-01]; and the Auvergne-Rhône Alpes Regional Council [SCUSI-1700937101] 


\footnotetext{
${ }^{i}$ Although an exhaustive overview of such policies throughout the world does not exist, it seems that most countries support clusters. In its 2010 Science and Technology Outlook, the OECD reviewed a set of 18 countries implementing a national cluster policy (Argentina, Canada, Chile, Austria, Belgium, China, Columbia, Denmark, France, Germany, Greece, Ireland, Japan, New Zealand, Sweden, Belgium, Netherlands). More recently, the European Observatory for cluster and industrial change (2019) stated that most EU countries implement a cluster policy and compared the national cluster programmes in 20 EU countries and 9 non EU countries (US, Brazil, Mexico, Israel, Taiwan, Singapore, China, Japan and South Korean).

ii An evaluation literature on cluster policies (Falk et al. 2010; Martin et al, 2011; Nishimura and Okamuro, 2011) and more widely collaboration-based policies (Sakakibara, 1997; Branstetter and Sakakibarra, 2002; Hottenroot and Lopes-Bento, 2014) does exist. However it focuses mainly on input and output additionality and neglect most of the time the behavioural additionality.

iii Modern cluster policies aim to establish a favourable business ecosystem for innovation and entrepreneurship in which new winners can emerge and thus support the development of new industrial value chains and "emerging industries". Smart Guide to Cluster Policy, European Union, 2016, p.11.

iv Broekel et al. (2015) explain the first of these additional premiums by the fact that cluster members have, on average, greater access to calls for (individual and joint) R\&D projects due to their stronger exposure to cluster internal knowledge spillovers and knowledge networks. The authors also point out that cluster members are more likely to receive $R \& D$ subsidies given the favourable conditions for knowledge production which they experience. Indeed, cluster members can rely on the cluster services (scientific monitoring, legal and market monitoring, interaction opportunities with experts and scientists, etc.) to conduct state-of-the-art and possibly excellent research and therefore likely to meet the high standards of subsidy schemes aiming at research excellence.

" It should be noted that in France, cluster members are actually firms' establishments where an "establishment" is defined as an independent production unit, physically located, but legally dependant of a firm. Several evaluations of the French cluster policy have been carried out by considering firms as treated units (Technopolis group et al., 2012; Fontagné et al., 2013; Bellégo and Dortet-Bernadet, 2014; Ben Hassine and Mathieu, 2017). Such evaluations could lead to inconsistent results, particularly when only some firms' establishments are cluster members while most of them are not.

${ }^{\text {vi }}$ The duration of projects often varies between 24 and 48 months.

vii The DADS database is administered by the French National Institute of Statistics and Economic Studies (INSEE). It provides employment information on the French directory of firms' establishments. Geographic information (address) from the DADS database was complemented with data from the free online business directory www.societe.com.

viii Our final dataset only contains establishments with complete information i.e., those that have no missing data in the DADS database.

${ }^{\text {ix }}$ It should be noticed that this variable would be biased if computed during the post-policy period since a cluster premium would exist allowing cluster members to be more likely to receive subsidies for collaborative R\&D projects (Broekel et al., 2015) and therefore being more collaborative.

“ Given the reasoning used in the generation of the variable "collaborative establishment", it already includes the information on participation in EU's Framework Programme before the policy (2005-2007). We therefore limit ourselves to generating the variable " $F P$ " only for the treatment period and used it as an explanatory variable in the response model in order to control for a potential effect of the Framework Programme on establishments' collaborative behaviour.

${ }^{x i}$ According to Directorate General for Enterprise (DGE, 2017), in 2014, 87\% of cluster member firms are SMEs, half of which (53\%) are micro-enterprises (employing fewer than ten people).
} 